NBER WORKING PAPERS SERIES

\title{
GOVERNMENT SOLVENCY, PONZI FINANCE AND THE REDUNDANCY \\ AND USEFULNESS OF PUBLIC DEBT
}

\author{
Willem H. Buiter
}

Kenneth M. Kletzer

Working Paper No. 4076

\author{
NATIONAL BUREAU OF ECONOMIC RESEARCH \\ 1050 Massachusetts Avenue \\ Cambridge, MA 02138 \\ May 1992
}

The authors want to acknowledge financial support from Ford Foundation Grant Number 920-0109, "Economics, Politics and Policies of Stabilization, Structural Adjustment and Long-term Development," administered by the Economic Growth Center of Yale University. This paper is part of NBER's research program in Public Economics. Any opinions expressed are those of the authors and not those of the National Bureau of Economic Research. 
NBER Working Paper \#4076

May 1992

\title{
GOVERNMENT SOLVENCY, PONZI FINANCE AND THE REDUNDANCY AND USEFULNESS OF PUBLIC DEBT
}

\begin{abstract}
We investigate how the ability of the govemment to depart from budget balance and issue debt expands the set of equilibria that can be supported using lump-sum tax-transfer instruments. We show how this depends on the restrictions that exist on the capacity to tax and make transfer payments, and what these restrictions imply for the government's ability to issue debt.

Central to our analysis is the definition of solvency for an infinite-lived govemment in an infinite-lived economy with overlapping generations of finite-lived households. Our specification is derived from the demand for public debt by private agents and the non-negativity constraints on the capital stock and on private consumption by all generations. Under fairly tight restrictions on the govemment's tax-transfer menu, our solvency constraint implies the conventional solvency constraint.

With unrestricted taxes and transfers Ponzi finance is always possible but "inessential": it does not expand the set of equilibria that can be supported. Ponzi finance can be "essential" when taxes and transfers are restricted. The paper establishes a number of results that demonstrate how the government's ability to issue debt allows restricted tax-transfer schemes to support all equilibria attainable using unrestricted taxes and transfers.
\end{abstract}

Willem H. Buiter

Department of Economics

Yale University

P.O. Box 1972

Yale Station

New Haven, CT 06520-1972

and NBER
Kenneth M. Kletzer

Economic Growth Center

Yale University

P.O. Box 1987

Yale Station

New Haven, CT 06520 


\section{(I) INTRODUCTION.}

Does the ability of the government to depart from budget balance and issue or retire debt expand or alter the set of equilibria that can be supported? We address this question for the case in which fiscal policy, involving, in addition to borrowing, the use of lump-sum taxes and transfers only, can be used for redistribution and insurance among heterogeneous households!. Heterogeneity is introduced using an OLG model without private intergenerational gifts 2 .

The answer turns out to depend crucially on the richness of the set of lump-sum tax-transfer instruments available and on the restrictions that this implies for the government's ability to issue debt. Central to the argument is our solvency constraint for an infinite-lived government ${ }^{3}$ in an infinite-lived economy with overlapping generations of finite-lived households. The government is solvent if its budgetary and financing policies are feasible currently and in all future periods. In our model, government solvency is expressed as a set of three inequality constraints on admissible sequences of taxes, transfers, public debt and exhaustive public spending. They are derived from the requirement that the capital stock and private consumption by each generation be non-negative in each period. In other words, solvency for the infinite-lived government is derived from the (well-understood) requirement of solvency (or non-bankruptcy) for each finite-lived household.

Consider economies in which the long-run real interest rate is above the long-run growth rate of efficiency labor. Under fairly tight restrictions on the ability of the government to use taxes and transfers freely, our solvency constraint implies the conventional solvency constraint, that the sequence of real public debt discounted at the real interest rate converges to zero. The first sufficient condition is that net transfer payments by the government to a generation during a period cannot change sign (from positive when young to negative when old) over that generation's life 
cycle. The second sufficient condition is that the long-run growth tate of transfers to the young and taxes on the old is less than the long-run interest rate. If, for instance, taxes and transfers cannot grow faster in the long tun than efficiency labor, or equivalently, if the ratio of taxes paid (transfers received) during a period by a generation to the value of the physical resources owned by it, is bounded, the second sufficient condition would be met.

Under less restrictive conditions on taxes and transfers, Ponzi finance may be possible, regardless of the relationship between the long-run real interest tate and the long-run real growth rate, and regardless of whether the economy is dynamically efficient or Pareto-efficient. We distinguish between essential Ponzi finance, that is Ponzi schemes that expand the set of equilibria for consumption and capital formation that can be supported, and inessential Ponzi finance that does not have any real effects. The same essential-inessential distinction is made for public debt as such. Whether or not public debt (Ponzi finance) is essential depends on the restrictions imposed on the government's ability to use taxes and transfers.

Ve establish three equivalence results4. The first states that with unrestricted time- and age-specific taxes and transfers, the ability to depart from budget balance does not permit additional equilibria to be supported. Specifically, any intergenerational redistribution and insurance that can be provided with government borrowing or lending can also be provided with a balanced government budget.

The second states that, if there are restrictions on the government's ability to levy age-specific taxes and make age-specific transfers during any given period, then the option of unbalancing the budget enhances the set of equilibria that can be supported. Specifically, if the government is constrained to have only age-independent taxes and transfers, the ability to 
unbalance the budget permits the government to support all the equilibria that can be supported with unrestricted age-specific taxes and transfers.

This second proposition vill not in general hold if the conventional government solvency constraint is imposed, and requires our less restrictive solvency constraint in order to be valid. Essential Ponzi finance characterizes the age-independent tax-transfer policies.

Our third equivalence proposition is that even rather severe restrictions on the variation of taxes and transfers over the lifetime of a generation do not restrict the equilibria that can be supported, provided unbalanced budgets are permitted. This result holds under the conventional solvency constraint and does not require Ponzi finance.

The substitution of government borroving for current lump-sum taxes (and such further future changes in lump-sum taxes, transfers and borroving as may be required to preserve government solvency) vill affect the equilibrium of an economy if it redistributes resources among private agents with different marginal propensities to spend. In the Samuelson [1958] overlapping generations (OLG) model used in our paper, there is heterogeneity between generations. Typically, postponing taxation through borroving or redistributing directly from the young to the old vill reduce aggregate saving. Such "financial crovding out" has been a central theme of macroeconomics.

Alternative government financing policies not only effect redistribution among generations, in a stochastic environment they vill also permit trades across states of nature or intergenerational insurance. There is by now quite a rich literature on this subject. Such intergenerational redistribution schemes as social security taxes and retirement benefits can provide insurance that either cannot be provided by the market or is provided inefficientlys. OLG models have 
incomplete market participation. Because individual households cannot enter into insurance contracts before they are born, there may be incomplete risk-sharing (Blanchard and Veil [1992]). Even in a dynamically. efficient economy, the public provision of this insurance can have implications for Pareto-efficiency (see Zilcha [1990] and Blanchard and Veil [1992]). ${ }^{\circ}$

Rather than investigating the many interesting positive and welfare aspects of intergenerational redistribution and of the provision of intergenerational insurance through the government budget (see e.g. Fischer [1983], Enders and Lapan [1982], Stiglitz [1983], Merton [1984], Gordon and Varian [1988], Pagano [1988] and Gale [1990]), we shall focus on the equivalence results, on the implications of our definition of government solvency, on the conditions under which Ponzi finance is possible and on the role of Ponzi finance.

The outline of the rest of this paper is as follows. Section II develops the model. Section III introduces our government solvency constraint, relates it to the conventional solvency constraint and discusses what it implies for the scope for Ponzi finance. Section IV contains our three equivalence results and analyzes how they depend on the ability of the government to engage in Ponzi finance. Section $V$ concludes.

\section{(II) THE MODEL.}

Consider the closed economy one-good version of Dianond's [1965] two-period OLG model with government borroving or lending and lump-sum taxes or transfers. Individuals of the same generation are identical. Successive generations have the same utility functions and maximize expected utility. People live for two periods, work in the first period of life and retire in the second. There is no intergenerational gift or bequest motive. Labor supply is inelastic and scaled to unity for each young worker. The young 
have access to two stores of value, claims on risky real capital and potentially risky public debt.?

The optimization problem of a competitive representative consumer born in period $t$ is given in equations (II.2) and (II.3a,b). $c_{t}^{j}$ and $\tau_{t}^{j}, j=1,2$, are consumption, respectively taxes paid, by a member of generation $t$ in the $j^{\text {th }}$ period of her life. $w_{t}$ is the wage rate in period $t$. $\quad \bar{k}_{t}^{d}$ and $\bar{b}_{t}^{d}$ are the amounts of capital, respectively bonds or securities, held by a member of generation $t$ at the end of period $t$. For simplicity, all securities are assumed to have a one-period maturity. $p_{t}$ is the price in period $t$ of a security that entitles one to a gross payment (coupon) of $\gamma_{t+1}$ units of output in period $t+1$, with a $>\gamma_{t+1}>0$. This payment may be stochastic. The one-period interest rate on debt carried into period $t+1, r_{t+1}$ is defined by

$$
1+r_{t+1} \equiv \gamma_{t+1} / p_{t}
$$

$\rho_{t+1}$ is the rental rate of a unit of capital in period $t+1 . E_{t}$ is the expectation operator conditional on information held at the beginning of period $t$.

$$
c_{t}^{l}, \mathrm{k}_{\mathrm{t}}^{\mathrm{d}}, \mathrm{b}_{\mathrm{t}}^{\mathrm{d}}, c_{\mathrm{t}}^{2} \mathrm{v}\left(c_{t}^{1}\right)+\beta \mathrm{E}_{\mathrm{t}} \mathrm{v}\left(c_{t}^{2}\right)
$$

subject to the sequence of budget constraints given in (II.3a,b).

$$
\begin{aligned}
& w_{t}-\tau_{t}^{I}-c_{t}^{I} \geq \bar{k}_{t}^{d}+p_{t} b_{t}^{d} \\
& c_{t}^{2}+\tau_{t}^{2} \leq\left(1+\rho_{t+1}\right) k_{t}^{d}+\gamma_{t+1} \bar{b}_{t}^{d} \quad \cdot 10
\end{aligned}
$$

Since utility is strictly increasing in $c^{1}$ and $c^{2}$, (II.3a,b) will hold with equality.

The interior first-order conditions 11 for a member of generation $t$ are

$$
\begin{aligned}
& v^{\prime}\left(c_{t}^{1}\right)=\beta E_{t}\left[\left(1+\rho_{t+1}\right) v^{\prime}\left(c_{t}^{2}\right)\right] \\
& v^{\prime}\left(c_{t}^{1}\right)=\frac{\beta}{p_{t}} E_{t}\left[\gamma_{t+1} v^{\prime}\left(c_{t}^{2}\right)\right] \equiv \beta E_{t}\left[\left(1+\tau_{t+1}\right) v^{\prime}\left(c_{t}^{2}\right)\right]
\end{aligned}
$$

Output $Y$ is produced by a twice continuously differentiable production function with constant returns to capital $I$ and labor in efficiency units $\theta L$ and 
positive and diminishing marginal products: $\frac{\mathrm{Y}_{\mathrm{t}}}{\theta_{\mathrm{t}} L_{t}} \equiv y_{t}=f\left(\frac{\mathbf{R}_{\mathrm{t}}}{\theta_{\mathrm{t}} L_{t}}\right)=f\left(k_{t}\right)$, $f^{\prime}>0 ; f^{\prime \prime}<0$. It also satisfies the Inada conditions. Productivity is modeled as labor-augmenting. $L$ is labor in natural units and $\theta$ the level of labor-augmenting productivity. $\theta$ can be random and is assumed to have positive support; for finite $t, \theta_{t}$ is also assumed to be bounded from above. Our equivalence results do not depend on this particular parameterization of uncertainty. The grouth rate of labor-augmenting productivity $\omega_{t}$ is defined by $1+w_{t} \equiv \theta_{t} / \theta_{t-1}$.

The labor market and capital rental market are competitive and clear, so

$$
\begin{aligned}
& w_{t}=\theta_{t}\left[f\left(k_{t}\right)-k_{t} f^{\prime}\left(k_{t}\right)\right] \\
& \rho_{t+1}=f^{\prime}\left(k_{t+1}\right) .
\end{aligned}
$$

The government imposes lump-sum taxes (transfers when negative) on the young and/or the old, spends a non-negative anount on public consumption ${ }^{13}$ and satisfies its single-period budget identity by borrowing or lending. $B_{t}$ is the stock of government bonds at the beginning of period $t$ and $G_{t}$ the amount of exhaustive public spending. The single-period government budget identity is

$$
\mathrm{p}_{\mathrm{t}} B_{t+1} \equiv 7_{\mathrm{t}} \mathrm{B}_{\mathrm{t}}+\mathrm{G}_{\mathrm{t}}-\tau_{t}^{1} L_{t}-\tau_{t-1}^{2} L_{t-1} \text {. }
$$

Population (assumed equal to the labor force) grows at the constant proportional rate $n>-1$. By choice of units we set $L_{0}=1$. With $b_{t} \equiv B_{t} /\left(\theta_{t} L_{t}\right)$, and $g_{t} \equiv G_{t} /\left(\theta_{t} L_{t}\right)$, the single-period government budget identity can be reuritten as

$$
\begin{aligned}
\mathrm{p}_{\mathrm{t}} b_{t+1}(1+n)\left(1+w_{\mathrm{t}+1}\right) & \equiv \gamma_{\mathrm{t}} b_{t}+\mathrm{g}_{\mathrm{t}}-\theta_{\mathrm{t}}^{-1}\left[\tau_{t}^{1}-\tau_{t-1}^{2}(1+n)^{-1}\right] \\
& \equiv\left(1+\mathrm{r}_{t}\right) \mathrm{p}_{\mathrm{t}-1} b_{t}+\mathrm{g}_{\mathrm{t}}-\theta_{\mathrm{t}}^{-1}\left[\tau_{t}^{1}-\tau_{t-1}^{2}(1+n)^{-1}\right]
\end{aligned}
$$

The economy-wide asset market equilibrium conditions are given by

$$
B_{t+1}=\mathrm{L}_{\mathrm{t}} \mathrm{b}_{\mathrm{t}}^{\mathrm{d}}
$$




$$
\boldsymbol{r}_{t+1}=\mathrm{L}_{\mathrm{t}} \mathrm{k}_{\mathrm{t}}^{-\mathrm{d}}
$$

Substituting the asset narket equilibrium conditions into (II.3a) yields:

$$
\left(\mathrm{p}_{\mathrm{t}} b_{t+1}+k_{t+1}\right)(1+n)\left(1+w_{t+1}\right)=\left(w_{t}-\tau_{t}^{1}-c_{t}^{1}\right) \theta_{\mathrm{t}}^{-1} \text {. }
$$

The lump-sum taxes levied (transfers paid) by the government and the coupon payment on the public debt can be stochastic. We assume for simplicity that the government does not introduce additional noise into the system $\left(G_{t}\right.$ is non-stochastic), but that taxes and debt coupon payments can be made contingent on current and past realizations of the random variable $\theta$. Let $\theta_{t}$ be the sequence of current and past realizations of $\theta$, that is $\theta_{t} \equiv\left\{\theta_{t-i} ; i \geq 0\right\}$.

$$
\begin{aligned}
& \tau_{t}^{1}=\tau_{t}^{1}\left(\theta_{t}\right) \\
& \tau_{t}^{2}=\tau_{t}^{2}\left(\theta_{t+1}\right) \\
& \gamma_{t}=\gamma_{t}\left(\theta_{t}\right)
\end{aligned}
$$

(III) GOVERITNT SOLVENCY AND PONZI FLNAKCE IN AN INFINITE-LIVED ECONOTY.

Solving the government single-period budget identity forward in time for $T \geq 0$ periods, we get for all $t \geq 0$

$$
\begin{aligned}
& \delta_{t-1} p_{t-1} b_{t} \equiv \sum_{i=0}^{T-1}\left(\theta_{t+i+1}\right)^{-1}\left[\frac{\tau_{t+i}^{1}}{1+n}+\left[\frac{1}{I+n}\right]^{2} \tau_{t+i-1}^{2}-\frac{g_{t+i}}{1+n}\right] \delta_{t+i} \\
& +\delta_{t-1+T} \mathrm{p}_{\mathrm{t}-1+\mathrm{T}^{\mathrm{b}} \mathrm{t}+T} \\
& \delta_{t+i} \equiv \prod_{j=0}^{t+i}\left[\frac{(1+n)\left(1+\omega_{j+1}\right)}{1+\Gamma_{j}}\right] \text { for } t+i \geq 0 \text {. } \\
& \equiv 1 \text { for } t+i=-1
\end{aligned}
$$

Ve also define the market discount factor $\Delta$ as follows:

$$
\Delta_{t+i} \equiv \prod_{j=0}^{t+i}\left[\frac{1}{1+\Gamma_{j}}\right]=\delta_{t+i} /\left(\theta_{t+i+1} L_{t+i+1}\right) \text {. }
$$

Note that $\delta$ is the "labor-force-growth-and-productivity-growth-adjusted" discount factor. Both $\Delta_{t+i}$ and $\delta_{t+i}$ are assumed to be positive for finite 
values of $t+i$ and non-negative in the limit as $t+i \rightarrow \infty$.

The conventional government solvency constraint, given in (III.3) requires the discounted public debt to vanish in the long run for any realization of the discounted debt sequence.

$$
\lim _{T \rightarrow \infty} \delta_{t-1+T} p_{t-1+T} b_{t+T} \equiv \lim _{T \rightarrow \infty} \Delta_{t-1+T} p_{t-1+T} B_{t+T}=0 . \quad 14
$$

Equations (III.3) implies (III.4)

$$
\delta_{t-1} \mathrm{p}_{\mathrm{t}-1} b_{t}=\lim _{\mathrm{T} \rightarrow \infty} \sum_{i=0}^{\mathrm{T}-1}\left(\theta_{\mathrm{t}+\mathrm{i}+1}\right)^{-1}\left[\frac{\tau^{1} \frac{1}{t+i}}{1+n}+\left[\frac{1}{1+n}\right]^{2} \tau_{t+i-1}^{2}-\frac{\mathrm{g}_{\mathrm{t}+\mathrm{i}}}{1+\mathrm{n}}\right] \delta_{t+i}
$$

The solvency condition (III.3) has the prima facie attractive property of implying the same kind of present value or intertemporal budget constraint (III.4) for the infinite horizon case as for the finite horizon case. If $t-1+T$ is the finite terminal period, then the standard (and uncontroversial) government solvency constraint is $p_{t-1+T} b_{t+T} \leq 0$ (the government doesn't owe anything at the end of the last period). A rational household sector ensures that $p_{t-1+T} b_{t+T} \geq 0$. From (III.1) these two veak inequalities imply, that the value of the current stock of debt is equal to the (expectation of) the present discounted value of future primary (non-interest) surpluses. This is the same as (III.4), with $\lim _{\mathrm{T} \rightarrow \mathrm{m}}$ dropped. The imposition of (III.3) has been quasi-automatic in modern macroeconomic analysis. For a very small sample see Barro [1979], Buiter [1985], Pagano [1988] and Blanchard et. al. [1990]. It has been the subject of extensive empirical testing (see e.g. Hamilton and Flavin [1986], Wilcox [1989], Corsetti [1990], Grilli [1990] and Buiter and Patel [1991]).

Ke believe that the analogy with the finite-horizon case is potentially misleading. It is by no means obvious what are, in an economy without a terminal date, the feasible debt strategies of an infinite-lived government 
facing an infinite sequence of finite-lived overlapping generations (see e.g. Shell [1971] and Vilson [1981]). As we shall see, without a-priori restrictions on taxes and transfers, our model has a surprising range of feasible debt strategies, many of which allow for Ponzi finance. Formally, Ponzi finance can be defined as follows for our model:

Definition 1: Ponzi finance.

The government engages in Ponzi finance if (III.5)

$$
p_{t} B_{t+1} \geq \tau_{t} B_{t} \equiv\left(1+r_{t}\right) p_{t-1} B_{t} \text { for all } t \geq 0.16
$$

The government engages in Ponzi finance if, in each period, $t$, the value of the debt carried into the next period, $t+1$, is at least as large as the cost of servicing the debt carried into period $t$. From the government's single-period budget identity it follows, that a government engages in Ponzi finance if $G_{t}-\left(\tau_{t}^{1} L_{t}+\tau_{t-1}^{2} L_{t-1}\right) \geq 0$ for all $t$, that is, if it never runs a primary (non-interest) budget surplus.

In Section IV ve are also interested in sequences of new debt minus old debt service, $\left\{p_{t} B_{t+1}-\left(1+r_{t}\right) p_{t-1} B_{t}\right\}_{t=0}^{\infty}$ that, while not themselves Ponzi schemes, possess infinite subsequences $\left.\left\{p_{t_{j}} B_{t_{j}+1}-\left(1+r_{t_{j}}\right) p_{t_{j}}-1^{B}\right\}_{j}\right\}_{t_{j}=0}^{\Phi}$ that are Ponzi schemes.

Ve proceed by investigating what kind of constraints the model of Section II imposes on the government's ability to issue debt. Equation (II.8), stating that the savings of the young in period $t$ equal the sum of the capital stock and the value of the stock of government debt carried into period $t+1$, can be rearranged as equation (III.6)

$$
p_{t} B_{t+1}+\tau_{t}^{1} L_{t}=-R_{t+1}+\left[w_{t}-c_{t}^{1}\right] L_{t}
$$


Equation (II.3b) (holding with equality), stating that the old consume all their after-tax resources, can be arranged as equation (III.7)

$$
\left(1+r_{t+1}\right) p_{t} B_{t+1}-\tau_{t}^{2} L_{t-1}=-\left(1+\rho_{t+1}\right) R_{t+1}+c_{t}^{2} L_{t}
$$

It is immediately obvious from (III.6) that, for given $K_{t+1}, w_{t}, c_{t}^{1}$ and $L_{t}$, the value of the public debt issued in period $t, \mathrm{p}_{t} \mathrm{~B}_{t+1}$ can be made arbitrarily large (positive or negative) by making matching large (positive or negative) period $t$ transfers to the young, $-\tau_{t}^{1} \mathrm{~L}_{t}$. Such an arbitrarily large (positive or negative) value of $p_{t} B_{t+1}$ is consistent with equation (III.7) for given $r_{t+1}, K_{t+1}, \rho_{t+1}, c_{t}^{2}$ and $L_{t}$, as long as period $\mathrm{t}+1$ taxes on the old, $\tau_{t}^{2} \mathrm{~L}_{\mathrm{t}}$ are assigned a matching large (positive or negative value).

Since $c_{t}^{1}$ and $R_{t+1}$ are non-negative, the constraint on public debt implied by (III.6) is $p_{t} B_{t+1}+\tau_{t}^{1} L_{t} \leq w_{t} L_{t}$. There also is a lover bound on the amount of public debt that can be issued (or an upper bound on the stock of public credit to the private sector). It follows from non-negativity of consumption by the old in period $t$. From the resource constraint $K_{t+1}-K_{t}=w_{t} L_{t}+\rho_{t} K_{t}-c_{t}^{1} L_{t}-c_{t-1}^{2} L_{t-1}-G_{t}$ and $c_{t-1}^{2} \geq 0$ it follows that $\left(w_{t}-c_{t}^{1}\right) L_{t}-G_{t}+\left(1+\rho_{t}\right) R_{t}-K_{t+1} \geq 0$. From (III.6) this implies $p_{t} B_{t+1}+\tau_{t}^{1} L_{t} \geq G_{t}-\left(1+p_{t}\right) R_{t}$

These upper and lower bounds on the public debt in each period, together with the requirement that exhaustive public spending cannot be negative and cannot exceed the total physical resources available in any period, constitute our definition of feasible fiscal policy. A solvent government is a government whose fiscal policy is feasible in a world with rational private agents ${ }^{17}$. 
Definition 2: Governent solvency.

A government is solvent if and only if its debt, taxes, transfer payments and exhaustive spending satisfy, for all $t \geq 0$

(III.8a)

$$
p_{t} B_{t+1}+\tau_{t}^{1} L_{t} \leq w_{t} L_{t}
$$

or, equivalently

(III.8 $\left.a^{\prime}\right)$

$$
\left(1+r_{t}\right) p_{t-1} B_{t}-\tau_{t-1}^{2} L_{t-1} \leq w_{t} L_{t}-G_{t}
$$

and

(III.8b)

$$
p_{t} B_{t+1}+\tau_{t}^{1} L_{t} \geq G_{t}-\left(1+p_{t}\right) K_{t}
$$

or, equivalently,

(III.86')

$$
\left(1+r_{t}\right) p_{t-1} B_{t}-\tau_{t-1}^{2} L_{t-1} \geq-\left(1+\rho_{t}\right) K_{t}
$$

Equations (III.8a and b) plus non-negativity of $G_{t}$ imply:

$$
0 \leq G_{t} \leq w_{t} L_{t}+\left(1+\rho_{t}\right) K_{t}
$$

Note that this definition of solvency can be generalized easily to all OLG models with finite household horizons. It relies only on the reasonable postulate that in the last period of its life, each household disposes of all real and financial assets (including public debt) and pays off any debts it has carried into that period and does not purchase any new assets or incur any new debt.

Since the government solvency constraint is derived from the requirement that $c_{t}^{1}, c_{t-1}^{2}$ and $R_{t} \geq 0$ for all $t \geq 0$, another way of interpreting it is that the government refrains from policies that will bankrupt the private sector: it does not select sequences for taxes, transfer payments, debt and exhaustive spending that will cause the non-negativity constraints on consumption by both generations and on the capital stock to become binding ${ }^{18}$.

The solvency conditions (III.8a and b') can be rewritten as

$$
\begin{aligned}
& p_{t} B_{t+1}+\tau_{t}^{1} L_{t} \leq\left[f\left(k_{t}\right)-k_{t} f^{\prime}\left(k_{t}\right)\right] \theta_{t}(1+n)^{t} \\
& \tau_{t-1}^{2} L_{t-1}-\left(1+r_{t}\right) p_{t-1} B_{t} \leq\left[1+f^{\prime}\left(k_{t}\right)\right] k_{t} \theta_{t}(1+n)^{t}
\end{aligned}
$$


Equation (III.9a) implies that the long-run growth rate of the total resource transfer from the young generation to the government (whether through purchases by the young of government debt or through taxes on the young) cannot exceed the long-run growth rate of efficiency labor. Note that there is no constraint on $\mathrm{p}_{t} \mathrm{~B}_{t+1}$ or $\tau_{t}^{1} \mathrm{~L}_{t}$ separately, only on their sum.

Equation (III.9b') implies that the long-run growth rate of the total resource transfer from the old generation to the government (whether through explicit taxes on the old or through the servicing of debt to the government incurred by the old) cannot exceed the long-run growth rate of efficiency labor. Note that there is no constraint on $\tau_{t-1}^{2} L_{t-1}$ or $\left(1+r_{t}\right) p_{t-1} B_{t}$ separately, only on their sun.

If the long-run interest rate exceeds the long-run growth rate of efficiency labor $\left.\left.\underset{t \rightarrow \infty}{\left(\lim _{t} \Delta_{t} \theta_{t}(1+n)\right.}\right)^{t}=0\right)$ then the solvency constraints (III.8a and b) imply

$$
\begin{aligned}
& \lim _{t^{\prime} \rightarrow \infty} \inf _{t^{\prime} \leq t \leq \infty}\left\{\Delta_{t}\left[p_{t} B_{t+1}+\tau_{t}^{1} L_{t}\right]\right\} \leq 0 \\
& \lim _{t^{\prime} \rightarrow \infty} \sup _{t^{\prime} \leq t \leq \infty}\left\{\Delta_{t}\left[p_{t} B_{t+1}+\tau_{t}^{1} L_{t}\right]\right\} \geq 0,
\end{aligned}
$$

If the limit inferior and the limit superior are the same, we get

$$
\lim _{t \rightarrow \infty} \Delta_{t}\left[p_{t} B_{t+1}+\tau_{t}^{1} L_{t}\right]=\lim _{t \rightarrow \infty}\left[\tau_{t-1}^{2} L_{t-1}-\left(1+r_{t}\right) p_{t-1} B_{t}\right]=0
$$

Note how this differs from the conventional solvency constraint $\lim _{t \rightarrow \infty} \Delta_{t} p_{t} B_{t+1}=0$. Equation (III.10) states that the present discounted value of the total resource transfer from the young to the government and the present discounted value of the total resource transfer from the old to the government should converge to zero. Without further restrictions on $\tau_{t}^{1}$ and $\tau_{t-1}^{2}$, equation (III.10) does not constrain the behavior of the public debt or the public credit in the long run. 
Ponzi finance with unrestricted taxes and transfers: a simple example.

As a simple illustration of the kind of borrowing policies that are feasible with unrestricted taxes and transfers, consider the deterministic version of our model with a logarithric utility function, $v\left(c_{t}^{1}\right)+\beta v\left(c_{t}^{2}\right)=(1-\eta) \ln c_{t}^{1}+\eta \ln c_{t}^{2}, 0 \leq \eta \leq 1$. The consumer's equilibrium in this case is given by

$$
\begin{aligned}
c_{t}^{1}=(1-\eta)\left(w_{t}-\tau_{t}^{1}-\frac{\tau_{t}^{2}}{1+r_{t+1}}\right) \\
c_{t}^{2}=\left(1+r_{t+1}\right) \eta\left(w_{t}-\tau_{t}^{1}-\frac{\tau_{t}^{2}}{1+r_{t+1}}\right) \\
p_{t} B_{t+1}+R_{t+1}=\left(w_{t}-c_{t}^{1}-\tau_{t}^{1}\right) L_{t} \\
=\left[\eta\left(w_{t}-\tau_{t}^{1}\right)+(1-\eta)_{1+r_{t+1}}\right] L_{t}
\end{aligned}
$$

Consumption when young and old, $c_{t}^{1}$ and $c_{t}^{2}$, are functions only of the present discounted value of life-time resources, $w_{t}-\tau_{t}^{1}-\frac{\tau_{t}^{2}}{1+r_{t+1}} \cdot$ Saving by the young (their aggregate demand for government bonds and real capital), hovever, is, for well-know life-cycle reasons, not a function of the present discounted value of 1 ife-time resources alone. Ve can revrite (III.13) as follows:

$$
B_{t+1}+R_{t+1}=\left[\eta\left(w_{t}-\tau_{t}^{1}-\frac{\tau_{t}^{2}}{1+r_{t+1}}\right)+\frac{\tau_{t}^{2}}{1+r_{t+1}}\right] L_{t}
$$

The young of period $t$ will demand more financial assets, cet. par., if they expect to have to pay a larger tax $\tau_{t}^{2}$ when they are old, regardless of the present discounted value of their life-time resources. The demand for saving by the young depends on the actual distribution of disposable (after-tax) resources over the lifetime. They will save more while young if 
the distribution of lifetime disposable resources is skeved towards youth. If the government has the ability to tax the members of any given generation differently when they are young than when they are old, it can influence the savings behavior of the young and with it the demand for its debt. By raising $\left[-\eta \tau_{t}^{1}+(1-\eta) \frac{\tau_{t}^{2}}{1+\Gamma_{t+1}}\right] \mathrm{L}_{t}$ while keeping $\tau_{t}^{1}+\frac{\tau_{t}^{2}}{1+\Gamma_{t+1}}$ and $G_{t}$ constant, the government can raise saving by the young by any amount without affecting consumption by the young or the old (or the demand for capital as a productive input). The government can therefore increase its debt without bound. Consider two equilibria, the single-star equilibrium and the double-star equilibrium. Assume that (III.14) holds for all $t \geq 0$, and that the initial capital stock $K_{0}$ and the sequence of exhaustive public spending in the two equilibria are identical.

$$
\tau_{t}^{1^{* *}}+\frac{\tau_{t}^{2^{* *}}}{1+r_{t+1}^{* *}}=\tau_{t}^{1^{*}}+\frac{\tau_{t}^{2^{*}}}{1+r_{t+1}^{*}}
$$

For concreteness, let the single-star equilibrium have a balanced budget in each period and zero public debt, that is

We define $\tau_{t}^{1 * *}$ and $\tau_{t-1}^{2^{* *}}$ as follows:

$$
\tau_{t}^{1 *} L_{t}+\tau_{t-1}^{2^{*}} L_{t-1}=G_{t} \text { and } B_{t}^{*}=0 \text { for all } t \geq 0
$$

$$
\tau_{t}^{1^{* *}}=\tau_{t}^{1^{*}}-\epsilon_{t} \text { and } \tau_{t-1}^{2^{* *}}=\tau_{t-1}^{2^{*}}\left(1+r_{t}\right) \epsilon_{t-1}
$$

It follows that

$$
\begin{aligned}
p_{t} B_{t+1}^{* *} & -\left(1+r_{t}\right) p_{t-1} B_{t}^{* *} \equiv G_{t}-\left[\tau_{t}^{1 * *} L_{t}+\tau_{t-1}^{2 * *} L_{t-1}\right] \\
= & G_{t}-\left[\left(\tau_{t}^{1 *}-\epsilon_{t}\right) L_{t}+\left(\tau_{t-1}^{2 *}\left(1+r_{t}\right) \epsilon_{t-1}\right) L_{t-1}\right] \\
= & {\left[(1+n) \epsilon_{t}-\left(1+r_{t}\right) \epsilon_{t-1}\right] L_{t-1} \cdot 19 }
\end{aligned}
$$

Thus, by choosing appropriately growing values for $\varepsilon_{t}, t \geq 0$, (that is values such that $\left.\epsilon_{t} / \epsilon_{t-1}>(1+n)^{-1}\left(1+r_{t}\right)\right)$, we can raise the growth rate of public debt in any period to any level. Since the present discounted value of 
lifetime taxes is the same in the single star and the double star equilibrium, the equilibrium private consumption sequences are the same, and so will be the vage rate, capital stock, interest rate and debt price sequences. By making a larger transfer to the young of generation $t$, the government provides the young with the means for increasing their saving. By levying a larger tax on that same generation when old, the government provides the young with an incentive to save in order to pay these higher taxes.

Since $\tau_{t}^{1 * *} L_{t}=\tau_{t}^{1 *} L_{t}-\epsilon_{t} L_{t}$ and $\tau_{t-1}^{2 * *} L_{t-1}=-\tau_{t}^{*} 1_{L}+\left(1+r_{t}\right) \epsilon_{t-1} L_{t-1}+G_{t}$, we note that when a Ponzi game is played $\left(\epsilon_{t} / \epsilon_{t-1}>(1+n)^{-1}\left(1+r_{t}\right)\right)$, the total tax on the young, $\tau_{t}^{1^{* *}} L_{t}$, will ultimately become negative and increasingly large in absolute value, while the tax on the old, $\tau_{t-1}^{2^{* *}} L_{t-1}$, will become an increasingly large positive number. Ve will therefore see the lifetime pattern of taxes becoming one of ever increasing receipts of transfer payments when young and ever increasing tax payments when old. The lifetime pattern of taxes therefore has to change sign or zig-zag.

It is obvious that this property generalizes to any finite household horizon OLG model: what is required is that in the last period of a household's life, the government be able to recoup in present value terms the non-balanced budget component of what it has transferred to the household in the earlier periods of its life.

Another way of interpreting this is that the debt can grow without bound (and at a rate higher than the interest rate) without affecting the equilibrium allocations for consumption and the capital stock, because the government can, effectively, tax the debt held by the old to pay for the servicing of the debt held by the old. Government debt held by the old increases the "base" on which lump-sum taxes on the old can be levied 20. McCallum [1984], made this point in the context of an infinite-lived 
representative agent model 21 (see also Bohn [1991]). Spaventa $[1987,1988]$ also emphasizes the distinction between models in which only endowments can be taxed (such as Pagano [1988]) and models in which interest income too is taxable. He, hovever, does not make the distinction between taxes on the young, taxes on the old and aggregate taxes. As we shall see below, aggregate taxes can be zero, and therefore less than the endowment (wage income) and less that the sum of the endowment and interest income, while the debt grows at a rate at least equal to the rate of interest forever.

Governent solvency and Ponzi finance vith and vithont restrictions on taxes and transfers.

The same point can be made slightly more generally by considering the full set of equilibrium conditions for our model. Given $k_{0}$ and $\gamma_{0} b_{0} \equiv\left(1+r_{0}\right) p_{-1} b_{0}$, a competitive equilibrium of the tro-period OLG model satisfies equations (III.16) to (III.20) for all $t \geq 0$.

$$
\begin{aligned}
& v^{\prime}\left(c_{t}^{1}\right)=\beta E_{t}\left[\left(1+f^{\prime}\left(k_{t+1}\right)\right] v^{\prime}\left(c_{t}^{2}\right)\right] \\
& v^{\prime}\left(c_{t}^{1}\right)=\frac{\beta}{p_{t}} E_{t}\left[\gamma_{t+1}\left(\Theta_{t+1}\right) v^{\prime}\left(c_{t}^{2}\right)\right\} \equiv \beta E_{t}\left[\left(1+r_{t+1}\right) v^{\prime}\left(c_{t}^{2}\right)\right] \\
& c_{t}^{2}+\tau_{t}^{2}\left(\Theta_{t+1}\right)=\theta_{t+1}(1+n)\left[\left(1+f^{\prime}\left(k_{t+1}\right)\right) k_{t+1}+\gamma_{t+1}\left(\theta_{t+1}\right) b_{t+1}\right] \\
& \equiv \theta_{t+1}(1+n)\left[\left(1+f^{\prime}\left(k_{t+1}\right)\right) k_{t+1}+\left(1+r_{t+1}\right) p_{t} b_{t+1}\right] \\
& \left\{\theta_{t}\left[f\left(k_{t}\right)-k_{t} f^{\prime}\left(k_{t}\right)\right]-\tau_{t}^{1}\left(\Theta_{t}\right)-c_{t}^{1}\right\} \theta_{t}^{-1} \\
& =\left(k_{t+1}+p_{t} b_{t+1}\right)(1+n)\left(1+w_{t+1}\right)
\end{aligned}
$$




$$
\begin{array}{r}
p_{t} b_{t+1}(1+n)\left(1+w_{t+1}\right) \equiv \gamma_{t}\left(\Theta_{t}\right) b_{t}+g_{t}-\theta_{t}^{-1}\left[\tau_{t}^{1}\left(\theta_{t}\right)+(1+n)^{-1} \tau_{t-1}^{2}\left(\theta_{t}\right)\right] \\
\equiv\left(1+r_{t}\right) p_{t-1} b_{t}+g_{t}-\theta_{t}^{-1}\left[\tau_{t}^{1}\left(\theta_{t}\right)+(1+n)^{-1} \tau_{t-1}^{2}\left(\theta_{t}\right)\right]
\end{array}
$$

It is clear by inspection of equations (III.16) to (III.19), that given the initial capital stock and government debt service, and for a give sequence of exhaustive public spending $g_{t}$, the solutions for consumption, $c_{t}^{1}$ and $c_{t-1}^{2}$, and the capital-labor ratio (in efficiency units), $k_{t+1}$, for all $t \geq 0$ are influenced by the remaining budgetary variables (taxes, transfers, public debt issues and public debt service) only through two terms. The first is $\left(1+\omega_{t+1}\right)(1+n) p_{t} b_{t+1}+\theta_{t}^{-1} \tau_{t}^{1}$, the total resource transfer from the young in period $t$ to the government, both through purchases of government debt and through explicit taxes. The second is $\left(1+r_{t}\right) p_{t-1} b_{t}-(1+n)^{-1} \theta_{t-1}^{-1} \tau_{t-1}^{2}$ $\equiv \gamma_{t} b_{t}+g_{t}-(1+n)^{-1} \theta_{t-1}^{-1} \tau_{t-1}^{2}$, the total resource transfer from the government to the old in period $t$, both through debt service and through explicit transfers to the old.

Note that, from (III.20), $(1+n)\left(1+w_{t+1}\right) p_{t} b_{t+1}+\theta_{t}^{-1} \tau_{t}^{1}$ $=g_{t}+\gamma_{t} b_{t}-(1+n)^{-1} \theta_{t}^{-1} \tau_{t-1}^{2}$ : what the government takes from the young in any given period, whether through borrowing or through taxes, it must either use to finance its exhaustive spending program or give to the old, through debt service or transfer payments. What the single-period government budget identity in (III.20) implies for the behavior of $p_{t} b_{t+1}, \gamma_{t} b_{t}, \tau_{t}^{1}$ and $\tau_{t-1}^{2}$ individually, is of no interest from the point of view of the behavior of consumption and the capital stock, once we know the behavior of $(1+n)\left(1+w_{t+1}\right) p_{t} b_{t+1}+\theta_{t}^{-1} \tau_{t}^{1}$ or of $\tau_{t} b_{t}-(1+n)^{-1} \theta_{t}^{-1} \tau_{t-1}^{2}$.

Ve now investigate how the solvency constraint, given in (III.8a,b and $\mathrm{c}$ ), is affected by various restrictions on the ability of the government to set age- and time-contingent taxes and transfers. We also 
investigate how such restrictions affect the government's ability to run Ponzi schemes and the implications for resource allocation of feasible Ponzi schenes.

Case 1: Unrestricted age- and tine-contingent taxes and transfers.

When there are no restrictions, other than those implied by (III8.a and b) on taxes and transfers, we can establish the following result.

Proposition 1.

With unrestricted age-, time- and state-contingent taxes and transfers, any equilibrium for consumption by the young and the old and for the capital stock, can be supported with an infinity of Ponzi schemes.

Proof: We assert that, if there exists an equilibrium (the single star equilibrium, say) $c_{t}^{1^{*}}, c_{t-1}^{2^{*}}, w_{t}^{*}, k_{t}^{*}, r_{t}^{*}, p_{t}^{*}, \tau_{t}^{1^{*}}, \tau_{t}^{2^{*}}, b_{t}^{*}$ for $t \geq 0$, for a given feasible sequence of exhaustive public spending, $g_{t}, t \geq 0$, then there also exist, for the same sequence of exhaustive public spending, (infinitely many) equilibria (the double star equilibria) $c_{t}^{1 * *}, c_{t-1}^{2^{* *}}, v_{t}^{* *}, k_{t}^{* *}, r_{t}^{* *}, p_{t}^{* *}$, $\tau_{t}^{1^{* *}}, \tau_{t}^{2^{* *}}, b_{t}^{* *}$ for $t \geq 0$ such that $c_{t}^{1^{* *}}=c_{t}^{1^{*}}, c_{t-1}^{2^{* *}}=c_{t-1}^{2^{*}}, w_{t}^{* *}=v_{t}^{*}$, $k_{t}^{* *}=k_{t}^{*}, r_{t}^{* *}=r_{t}^{*}, p_{t}^{* *}=p_{t}^{*}$ and $p_{t}^{* *} b_{t+1}^{*}-p_{t-1}^{* *} b_{t}^{*}(1+n)^{-1}\left(1+\omega_{t+1}\right)^{-1} \geq$ $r_{t}^{* *} p_{t-1}^{* *} b_{t}^{*}(1+n)^{-1}\left(1+w_{t+1}\right)^{-1}$ for all $t \geq 0$

For the double star taxes and debt to support the same consumption and capital stock equilibrium, it is necessary and sufficient that

$$
(1+n)\left(1+w_{t+1}\right)^{-1} p_{t}^{*} b_{t+1}^{*}+\theta_{t}^{-1} \tau_{t}^{1^{*}}=(1+n)\left(1+w_{t+1}\right)^{-1} p_{t}^{*} b_{t+1}^{* *}+\theta_{t}^{-1} \tau_{t}^{1 * *}
$$

or

$$
\gamma_{t} b_{t}^{*}-(1+n)^{-1} \theta_{t}^{-1} \tau_{t-1}^{2^{*}}=\gamma_{t} b_{t}^{* *}-(1+n)^{-1} \theta_{t}^{-1} \tau_{t-1}^{2^{* *}} \quad \text { for all } t \geq 0 \text {. }
$$

For the debt to grow at least as fast as the rate of interest forever, it 
must be true that for all $t \geq 0$

$$
(1+\mathrm{n})\left(1+w_{t+1}\right) p_{t}^{*} b_{t+1}^{* *}-\left(1+r_{t+1}\right) p_{t-1}^{*} b_{t}^{* *}=g_{t}-\theta_{t}^{-1}\left[\tau_{t}^{1^{* *}}+\tau_{t-1}^{2 * *}(1+n)^{-1}\right] \geq 0
$$

The two choice variables during period $t$ in equation (III.22) are $\tau_{t}^{1^{* *}}$ and $\tau_{t-1}^{2^{* *}}$. No matter what value is assigned to $\tau_{t-1}^{2^{* *}}, \tau_{t}^{1^{* *}}$ can alvays be assigned a large enough negative value to ensure that (III.22) is satisfied: the debt grows at least as fast as the rate of interest.

From the single-period government budget identity, it follows that (III.21a) and (III.21b) are the same constraint. No matter what value is assigned to $\tau_{t}^{1 * *}$, a value can be assigned to $\tau_{t-1}^{2 * *}$ that ensures that (III.21a,b) are satisfied for any values of $\tau_{t}^{1^{*}}, \tau_{t-1}^{2^{*}}, b_{t}^{*}, b_{t+1}^{*}, b_{t}^{* *}$ and $b_{t+1}^{* *} \cdot a$

Another vay of putting this is that, by increasing $-\tau_{t}^{1 * *} L_{t}$ for any given values of $\tau_{t-1}^{2 * *} L_{t-1}$ and $G_{t}$ and for any inherited value of $\left(1+r_{t}\right) p_{t-1} B_{t}^{* *}$, it is possible to raise the grovth rate of the public debt to any positive level without affecting $p_{t} B_{t+1}^{* *}+\tau_{t}^{1 * *} L_{t}$, the term on the left-hand side of the solvency constraints (III.8a and b). $\tau_{t-1}^{2^{* *}} L_{t}$ can then be chosen to ensure that $\left(1+r_{t}\right) p_{t-1} B_{t}^{* *}-\tau_{t-1}^{2 * *} L_{t-1}$, the term on the left-hand side of (III.8a' and $b^{\prime}$ ) satisfies these inequalities. The government simply reshuffles a constant total resource transfer avay from the young in period $t, p_{t} B_{t+1}^{* *}+\tau_{t}^{1^{* *}} L_{t}$, between borroved resources, $p_{t} B_{t+1}^{* *}$, and explicit taxes, $\tau_{t}^{1^{* *}} L_{t} \cdot$ Appropriating for its own use an amount of resources equal to the value of exhaustive public spending, $G_{t}$, it pays out the remainder to the old, either as debt service, $\left(1+r_{t}\right) p_{t-1} B_{t}^{* *}$ or as transfers $-\tau_{t-1}^{2^{* *}} L_{t}$. Again it is only the total, $\left(1+r_{t}\right) p_{t-1} B_{t}^{* *}-\tau_{t-1}^{2 * *} L_{t}$ that matters for the consumption of the old. 
Corollary.

With unrestricted taxes and transfers, the competitive equilibrium model with the finite-lived OLG household sector does not require any bounds on the level or rate of growth of public debt. Ponzi finance is therefore always possible, regardless of the relationship between the interest rate and the growth rate, regardless of whether the economy is dynamically efficient and regardless of whether the economy is Pareto-efficient.

Case 2: Restrictions on differences in taxes and transfers in any period for overlapping generations.

Three interesting restrictions fitting this category come to mind.

(a) Equal taxes or transfers per generation for all generations alive during any given period.

In this case $\tau_{t}^{1}(1+n)=\tau_{t-1}^{2}$ for all $t \geq 0$. In Section (IV) we show that this restriction does not bite. The long-run grovth rate of the debt (over 2-period intervals) equals the interest rate, even when the interest rate is above the growth rate of efficiency labor. Such Ponzi finance subsequences are "essential": without them the restrictions on taxes and transfers vould affect the equilibria that can be supported.

(b) Equal per capita taxes or transfers for all generations alive during any given period.

In this case $\tau_{t}^{1}=\tau_{t-1}^{2}$ for all $t \geq 0$. In Section (IV) we show that this restriction too does not bite. The long-run growth rate of the debt (over 2 period intervals) equals the sum of the interest rate and the growth rate of the labor force. Essential Ponzi finance subsequences therefore play a role whenever the growth rate of the labor force is non-negative. 
(c) Equal taxes per unit of efficiency labor for all generations alive during any given period.

In this case $\tau_{t}^{1}=\left(1+w_{t}\right) \tau_{t-1}^{2}$ for all $t \geq 0$. In Section (IV) we also show this restriction to be toothless. The long-run growth rate of the debt (over 2-period intervals) is the sum of the interest rate and the growth rate of efficiency labor. Such Ponzi finance subsequences are essential.

What drives these results is that even though the two generations (the young and the old) alive in any given period are treated in the same way during that period, we can still vary taxes and transfers freely over the life-cycle of each generation, making transfer payments to them while young and taxing them when old.

Case 3: Restrictions on variations in taxes and transfers over its lifetine for any given generation.

The most interesting restriction is that net taxes in each of the two periods of a household's life must have the same sign, that is

$$
\tau_{\mathrm{t}}^{2}=\lambda_{\mathrm{t}} \tau_{\mathrm{t}}^{1} \quad \lambda_{\mathrm{t}} \geq 0 \text { for all } \mathrm{t} \geq 0 \text {. }
$$

Ve need just one of the weak inequalities of the solvency constraint in order to show that, under this restriction, Ponzi finance is possible only if the interest rate is below the growth rate of efficiency labor. Consider equations (III.8a) and (III.8a'), rewritten for this case as

(III.23a) $p_{t} B_{t+1} \leq\left[f\left(k_{t}\right)-k_{t} f^{\prime}\left(k_{t}\right)\right] \theta_{t} L_{t}-\tau_{t}^{1} L_{t}$ (III.23b) (1+r $\left.{ }_{t+1}\right) p_{t} B_{t+1} \leq\left[f\left(k_{t+1}\right)-k_{t+1} f^{\prime}\left(k_{t+1}\right)\right] \theta_{t+1} L_{t+1}+\lambda_{t} \tau_{t}^{1} L_{t}-G_{t+1}$

From (III.23a), the only way for the debt to grow faster than the growth rate of efficiency labor forever, is for $\tau_{t}^{1}$ to be negative and for $-\tau_{t}^{1}$ to grow at a rate higher than the growth rate of labor productivity. If the debt grows faster than the growth rate of efficiency labor forever, (III.23b) can 
only be satisfied if $\lambda_{t} \tau_{t}^{1} L_{t}$ is positive and has a grovth rate higher than the growth rate of efficiency labor. That is impossible since $\lambda_{t} \geq 0$. Ve conclude that $-\tau_{t}^{1}$ can grow no faster than the growth rate of lahor productivity and that the growth rate of the debt can therefore be no higher than the growth rate of efficiency labor. The debt can therefore grow faster than the interest rate forever only if the interest rate is helow the grovth rate of efficiency labor.

Note that Case 3 includes quite a variety of fiscal rules, including per capita taxes (or transfers) constant across generations at a point in time, and groving over time at a constant proportional rate $\nu$, that is $\tau_{t}^{1}=\tau_{t-1}^{2}=$ $\tau_{t}=\tau_{0}(1+\nu)^{t}$ for all $t \geq 0$. Note that our argument implies that $\nu$ cannot be permanently higher that the grovth rate of labor productivity.

Blanchard and Veil [1992] considered the special case of this model where the lahor force is constant $(n=0)$, there is no productivity growth $\left(\theta_{t}=\theta\right.$ for all $t \geq 0)$, there is no exhaustive puhlic spending $\left(G_{t}=0\right.$ for all $\left.t \geq 0\right)$ and there are no taxes or transfers $\left(\tau_{0}=0\right)$. In their model, debt obviously cannot grow faster than vage income in the long run. In the deterministic version of their model, this means that only in a dynamically inefficient equilibrium can there be viable Ponzi schemes, with the puhlic deht groving forever at least as fast as the interest rate but no faster than the growth rate of labor income.

In general (that is, even if net taxes can change sign over the life cycle), if the long-run rate of interest exceeds the long-run grovth rate of the disposable income of the young (vages net of taxes on the young), that is, if $\lim _{t \rightarrow \infty}\left\{\Delta_{t}\left[\theta_{t}\left(f\left(k_{t}\right)-k_{t} f^{\prime}\left(k_{t}\right)\right)-\tau_{t}^{1}\right](1+n)^{t}\right\}=0$, equations (III.8a, or $a^{\prime}$ ) imply 
(III.24)

$$
\lim _{t^{\prime} \rightarrow \infty} \inf _{t^{\prime} \leq t<\infty}\left\{\Delta_{t} p_{t} B_{t+1}\right\} \leq 0
$$

From the public credit constraint (III.8b) or (III.8b') it follows that, if the long-run rate of interest exceeds the rate of growth of the disposable income of the old (capital income minus taxes on the old), that is, if $\lim _{t \rightarrow \infty}\left\{\Delta_{t}\left[\left(1+f^{\prime}\left(k_{t}\right)\right) k_{t} \theta_{t}-(1+n)^{-1} \tau_{t-1}^{2}\right](1+n)^{t}\right\}=022$, we have

$$
\lim _{t \rightarrow \infty} \sup _{t^{\prime} \leq t \leq \infty}\left\{\Delta_{t} p_{t} B_{t+1}\right\} \geq 0
$$

If $\lim _{t^{\prime} \rightarrow \infty} \inf _{t^{\prime} \leq t \leq \infty}\left\{\Delta_{t} p_{t} B_{t+1}\right\}=\lim _{t^{\prime} \rightarrow \infty} \sup _{t^{\prime} \leq t \leq \infty}\left\{\Delta_{t} p_{t} B_{t+1}\right\}=0$, then we also have $\lim _{t \rightarrow \infty} \Delta_{t} p_{t} B_{t+1}=0$. This means that when the long-run rate of interest exceeds the long-run growth rate of the disposable income of the young and of the old, the conventional solvency constraint emerges.

If the taxes paid (transfers received) by each generation are distortionary, it is unlikely that the long-run grovth rate of per capita taxes (transfers) can exceed the long-run growth rate of productivity. There will be some finite upper bound on the ratio of taxes and transfers per generation to the real (physical) resources owned by that generation. Tax administration and collection costs that are strictly convex functions of the amount of taxes raised, will also put a finite upper bound on the ratio of taxes paid to real resources onned (see Barro [1976], McCallum [1984], Kremers [1989] and Bohn [1991]).

Ve sumarize the foregoing discussion in the following Proposition: 
Proposition 2.

The conventional government solvency constraint $\left(\lim _{t \rightarrow \infty} \Delta_{t} p_{t} B_{t+1}=0\right)^{23}$ is implied by our solvency constraint (III.8a,b and c) if

(a) The long-run interest rate exceeds the long-run growth rate of efficiency labor $\left(\lim _{t \rightarrow \infty} \Delta_{t} \theta_{t}(1+n)^{t}=0\right)$

and

(b) Either, the net tax paid by any generation at a given age cannot change sign over the lifetime of that generation, or, the long-run growth rate of taxes paid or transfers received at a given age by a generation is less than the long-run rate of interest.

In order for the public debt to grow at least as fast as the rate of interest forever, when the rate of interest is above the growth rate of efficiency labor, it must be possible to make transfer payments to a generation when it is young and to tax it when it is old; in addition, the growth rate of these taxes and transfers must be at least as high as the interest rate24. Note that it is only the taxes on or transfers to each generation that must have a growth rate at least as high as the interest rate. Aggregate taxes net of transfers, $\tau_{t}^{1} \mathrm{~L}_{t}+\tau_{t-1}^{2} \mathrm{~L}_{t}$, need not grow at all, as Case 4 below makes clear.

Case 4: Restrictions on hor taxes can change fron period to period.

Ve consider the example of age-specific taxes groving at a common (but not necessarily constant) growth rate, that is $\tau_{t}^{1}=\tau_{t-1}^{1}\left(1+\phi_{t}\right)$ and $\tau_{t-1}^{2}=\tau_{t-2}^{2}\left(1+\phi_{t}\right)$ for all $t \geq 0$. This is an interesting case because in many models, taxes on the young will grow, from one generation to the next, at the 
same rate as taxes on the old in steady state. We define $\Psi_{t} \equiv \prod_{j=0}^{t}\left(1+t_{j}\right), t \geq 0$.

In this case the relevant solvency constraints become

$$
\begin{aligned}
& G_{t}-\left(1+p_{t}\right) R_{t} \leq p_{t} B_{t+1}+\tau_{0}^{1} \Psi_{t}(1+n)^{t} \leq w_{t} L_{t} \\
& -\left(1+p_{t}\right) K_{t} \leq\left(1+r_{t}\right) p_{t-1} B_{t}-\tau_{-1}^{2} \Psi_{t}(1+n)^{t-1} \leq w_{t} L_{t}-G_{t}
\end{aligned}
$$

Let $\tau_{0}^{1}$ be negative and $\tau_{-1}^{2}$ positive, with $\tau_{0}^{1}+(1+n)^{-1} \tau_{-1}^{2}=0$. As long as $\Psi_{t}$ is positive, the public debt always grows at least as fast as the rate of interest, since $p_{t} B_{t+1}-\left(1+r_{t}\right) p_{t-1} B_{t} \equiv G_{t}-\left[\tau_{0}^{1}+(1+n)^{-1} \tau_{-1}^{2}\right] \Psi_{t}(1+n)^{t}$ and $G_{t} \geq 0$. The actual value of $\phi_{t}$ (and thus of $\Psi_{t}$ ) each period can be chosen so as to keep $p_{t} B_{t+1}+\tau_{0}^{1} \Psi_{t}(1+n)^{t}$ invariant under different choices of $\phi_{t}$, and independent of the growth rate of of $p_{t} B_{t+1}$.

Despite these restrictions, we can still make transfer payments to the young and impose taxes on the old. In addition, we can choose, each period, the common growth rate of per capita taxes on the old and per capita transfer payments to the young. If $G_{t}=0$ for all $t$, we can make the growth rate of public debt exactly equal to the interest rate each period.

(IV) TBREE EQUTVALENCE RESULTS.

We can now can state our first equivalence result:

\section{Proposition 3.}

Given initial values $k_{0}$ and $b_{0}$ and a feasible sequence $g_{t^{\prime}} t \geq 0$, any equilibrium for $p_{t}, k_{t}, c_{t}^{1}$ and $c_{t}^{2}$ with arbitrary paths of debts $b_{t}$ and of lump-sum taxes and transfers $\tau_{t}^{1}$ and $\tau_{t}^{2}$ for all $t \geq 1$ can be replicated without debt and deficits, that is by using balanced-budget lump-sum taxes and transfers only. 
What this means is that, in a deterministic model, any intergenerational redistribution that can be supported by debt and taxes can also be supported just with taxes and without debt. In the stochastic case it is true in addition that any intergenerational insurance supported with public debt, unbalanced budgets and ageand generation-dependent lump-sum taxes can also be provided with a balanced budget and without public debt.

Proof: An equilibrium is characterized for all $t \geq 0$ by equations (III.16) to (III.20), the government solvency constraint given in (III.8a, b, and c) and initial conditions $k_{0}$ and $b_{0}$. Ve rewrite the first two inequalities of the solvency constraint as follows:

$$
\left(1+w_{t+1}\right)(1+n) p_{t} b_{t+1}+\theta_{t}^{-1} \tau_{t}^{1} \leq f\left(k_{t}\right)-z_{t} f^{\prime}\left(k_{t}\right)
$$

or

$$
\begin{aligned}
& \left(1+r_{t}\right) p_{t-1} b_{t}-\left(1+w_{t+1}\right)^{-1}(1+n)^{-1} \tau_{t-1}^{2} \leq f\left(x_{t}\right)-k_{t} f^{\prime}\left(x_{t}\right)-g_{t} \\
& \left(1+w_{t+1}\right)(1+n) p_{t} b_{t+1}+\theta_{t}^{-1} \tau_{t}^{1} \geq g_{t}-\left(1+p_{t}\right) x_{t}
\end{aligned}
$$

or

$$
\left(1+r_{t}\right) p_{t-1} b_{t}-\left(1+w_{t+1}\right)^{-1}(1+n)^{-1} \tau_{t-1}^{2} \geq-\left(1+\rho_{t}\right) x_{t}
$$

The proof is direct and constructive. We first consider a "reference equilibrium" supported by given sequences of taxes and debt, denoted by single overbars. Next we propose an alternative set of sequences of taxes and debt (denoted by double overbars), which include the balanced-budget, zero public debt sequences. Finally, we check by direct computation that the double overbar sequences support the same equilibrium sequences of consumption and capital accumulation as the single overbar sequences (note that exhaustive public spending is the same under both policies). Formally, consider paths $\bar{b}_{t}, \bar{\tau}_{t}^{1}$ 
and $\bar{\tau}_{t}^{2}$ for all $t \geq 0$ that support equilibrium paths $\mathrm{p}_{\mathrm{t}}, k_{t}, c_{t}^{1}$ and $c_{t}^{2}$ for all $t \geq 1$ for given $k_{0}$ and $b_{0}$. Ne show that for any other set of debt paths $\bar{b}_{t}, t \geq 1$, there exists associated paths for lump-sum taxes and transfers $\bar{\tau}_{t}^{1}$ and $\bar{\tau}_{t}^{2}, \mathrm{t} \geq 0$ that support the same equilibrium paths $p_{t}, k_{t}, c_{t}^{1}$ and $c_{t}^{2}$ for $t \geq 1$. Let the double overbar debt and tax sequences satisfy (IV.3) and (IV.4)

$$
\begin{aligned}
& \mathrm{p}_{\mathrm{t}}\left(\bar{b}_{t+1}-\bar{b}_{t+1}\right)=\left[\frac{1}{1+n}\right] \theta_{\mathrm{t}+1}^{-1}\left[\bar{\tau}_{t}^{1}\left(\Theta_{\mathrm{t}}\right)-\bar{\tau}_{t}^{1}\right] \text { for all } t \geq 0 \\
& {\left[\begin{array}{l}
\left.\bar{\tau}_{t}^{2}-\bar{\tau}_{t}^{2}\left(\Theta_{\mathrm{t}}\right)\right]=\gamma_{\mathrm{t}+1}\left(\Theta_{\mathrm{t}+1}\right)\left[\overline{\mathrm{b}}_{t+1}-\overline{\mathrm{b}}_{t+1}\right.
\end{array}\right] \theta_{\mathrm{t}+1}(1+\mathrm{n})}
\end{aligned}
$$

Equations (IV.3) and (IV.4) imply (IV.5)

$$
\begin{aligned}
-\left[\bar{\tau}_{1}-\bar{\tau}_{t}^{1}\left(\Theta_{\mathrm{t}}\right)\right] & =\frac{\mathrm{p}_{\mathrm{t}}}{\gamma_{\mathrm{t}+1}\left(\Theta_{\mathrm{t}+1}\right)}\left[\bar{\tau}_{t}^{2}-\bar{\tau}_{t}^{2}\left(\Theta_{\mathrm{t}+1}\right)\right] \\
& \equiv \frac{1}{1+r_{t+1}}\left[\bar{\tau}_{t}^{2}-\bar{\tau}_{t}^{2}\left(\Theta_{\mathrm{t}+1}\right)\right] \text { for all } t \geq 025
\end{aligned}
$$

Equation (IV.3) ensures that the economy-vide capital market equilibrium condition (III.19) will be satisfied for the same values of $\mathrm{p}_{\mathrm{t}}, c_{t}^{1}, c_{t}^{2}$ and $k_{t}$ (and therefore also the same values of $w_{t}$ ). Equation (IV.4) ensures that the budget constraint of the old in period $t$ given in (III.18) will be satisfied for the same values of $c_{t}^{2}, k_{t+1}$ and $r_{t+1}$. It is easily verified that the government budget identity in (III.20) will also be satisfied under the double overbar policies. Finally, it is obvious that if the government solvency constraint is satisfied for the single overbar policy it will also be satisfied for the double overbar policy.

The remaining equilibrium conditions (III.16), and (III.17) also hold under the double overbar policy. To get Proposition 1 we set $\bar{b}_{t}=0$ for all $t \geq 1.0$

Thus any equilibrium with government debt and deficits can be replicated 
by an economy in which the government budget is balanced period-by-period (and the stock of debt is zero) by appropriate age-specific lump-sum taxes and transfers.

It can be checked easily that, if the conventional government solvency constraint (III.3) is satisfied under the single overbar policy, it is also satisfied under the double overbar policy. The validity of Proposition 3, unlike that of Proposition 4 and its Corollaries below, is therefore not dependent on the acceptability of our generalized solvency constraint. The reason is that under the double overbar policy in the proof of Proposition 2, taxes and transfers are not in any way restricted.

Proposition 3 is a generalization of the vell-known proposition that an equilibrium with positive public debt financed by taxes on the young is equivalent to a balanced budget, pay-as-you-go (or unfunded) social security retirement scheme in which lump-sum taxes on the young are paid out as lump-sum transfers to the old. Calvo and Obstfeld [1988a,b] proved it for a non-stochastic model.

Corollary 1.

With unrestricted lump-sum taxes and transfers, public debt is redundant or "inessential", that is, it does not permit additional equilibria to be supported.

\section{Corollary 2.}

With unrestricted taxes and transfers, Ponzi finance is "inessential", that is, it does not permit additional equilibria to be supported. 


\section{Proposition 4.}

Given an initial value $k_{0}$ and a sequence of exhaustive public spending $g_{t}, t \geq 0$, any equilibrium for $p_{t}, k_{t}, c_{t}^{1}$ and $c_{t-1}^{2}$ for all $t \geq 0$ supported by age-and time-dependent lump-sum taxes and transfers but without public debt and with balanced public sector budgets, can also be supported with age-independent (equal per capita for both generations alive in any given period) lump-sum taxes and transfers, provided unbalanced public sector budgets are allowed.

This means that any intergenerational redistribution and intergenerational insurance supported with balanced-budget age-dependent lump-sum taxes and transfers, can also be supported with age-independent lump-sum taxes and tranfers but with unbalanced public sector budgets. Note that, from Proposition 3, there is no loss of generality in taking the benchmark equilibrium of Proposition 4 to have a balanced budget and zero public debt.

Ve shall give a detailed proof only for the case where the unbalanced budget, age-independent tax-transfer policy involves equal per capita taxes on both generations alive in any given period (Case $2 b$ ) of our taxonomy in Section III. The proofs for equal taxes per generation (Case 2a) and equal taxes per efficiency unit of labor (Case 2c) are virtually identical.

Proof: Variables with single overbars represent the benchmark balanced-budget policy with age-dependent taxes and transfers. Variables vith double overbars represent the age-independent tax/transfer case with an unbalanced budget.

Note that $\bar{b}_{t}=0, \bar{\tau}_{t}^{1}=-(1+n)^{-1} \bar{\tau}_{t-1}^{2}+\theta_{t} g_{t}$ and $\bar{\tau}_{t-1}^{2}=\bar{\tau}_{t}^{1}=\bar{\tau}_{t}$ for all $t \geq 0$.

From equation (III.18) it follows that, if equivalence holds, it must be 
true that

$$
\mathrm{p}_{\mathrm{t}} \overline{\mathrm{b}}_{\mathrm{t}+1}=\left(1+\mathrm{r}_{\mathrm{t}+1}\right)^{-1} \theta_{\mathrm{t}+1}^{-1}\left[\bar{\tau}_{\mathrm{t}+1}^{-1}+\overline{\bar{\tau}}_{\mathrm{t}+1}(1+\mathrm{n})^{-1}-\theta_{\mathrm{t}+1} \mathrm{~g}_{\mathrm{t}+1}\right]
$$

From (IV.7) and the government's single-period budget identity, (or equivalently from the economy-wide capital market equilibrium condition (III.19)), it follows that, if the double overbar regime supports the same equilibria as the single overbar regime, it must be true that (IV.8) holds.

$$
\mathrm{p}_{\mathrm{t}} \overline{\bar{b}}_{\mathrm{t}+1}=(1+\mathrm{n})^{-1} \theta_{\mathrm{t}+1}^{-1}\left[\bar{\tau}_{\mathrm{t}}^{1}-\overline{\bar{\tau}}_{\mathrm{t}}\right]
$$

For any $\bar{\tau}_{t}^{1}$ is is clear that a value of $\overline{\bar{\tau}}_{t}$ can be found to satisfy (IV.7) and (IV.8). The other equilibrium conditions (III.16) and (III.17) are also satisfied under the double overbar regime. The solvency constraint under the single overbar regime is

$$
\theta_{t}^{-1} \bar{\tau}_{t}^{1} \leq f\left(k_{t}\right)-k_{t} f^{\prime}\left(k_{t}\right)
$$

and

$$
\theta_{t}^{-1} \bar{\tau}_{t}^{1} \geq g_{t}-\left(1+\rho_{t}\right) k_{t}
$$

Onder the double overbar regime the solvency constraint is

$$
p_{t} \bar{b}_{t+1}+(1+n)^{-1} \theta_{t+1}^{-1} \overline{\bar{\tau}}_{t}^{1} \leq f\left(k_{t}\right)-k_{t} f^{\prime}\left(k_{t}\right)
$$

and

$$
p_{t} \bar{b}_{t+1}+(1+n)^{-1} \theta_{t+1}^{-1} \overline{\bar{\tau}}_{t}^{1} \geq g_{t}-\left(1+p_{t}\right) k_{t}
$$

It is clear from (IV.8) that if the solvency constraint is satisfied under the single over-bar regime ((IV.9) and (IV.10) hold), then it will also be satisfied under the double overbar regime ((IV.11) and (IV.12) hold). D

While this completes the proof of Proposition 4, it is instructive to investigate the behavior of taxes and of the public debt under the double overbar regime. It turns out that Ponzi finance of a special kind (the sequence of government debt will have infinite subsequences that grow faster than the rate of interest forever if the population grovth rate is positive), 
will in general be necessary for the age-independent tax-transfer regime to support the same equilibria as the unrestricted tax-transfer regime. Ponzi finance is therefore essential under the restricted tax-transfer scheme.

Equations (IV.7) and (IV.8) imply

$$
\overline{\bar{\tau}}_{t+1}=-\left(1+\mathrm{r}_{\mathrm{t}+1}\right) \overline{\bar{\tau}}_{t}+\left(1+\mathrm{r}_{\mathrm{t}+1}\right) \bar{\tau}_{t}^{1}-(1+\mathrm{n}) \bar{\tau}_{t+1}^{1}+(1+\mathrm{n}) \theta_{\mathrm{t}+1} \mathrm{~g}_{\mathrm{t}+1}
$$

At a given rate of interest, the unfunded balanced-budget social security scheme (the single overbar scheme) increases the period $t+1$ value of the lifetime resources of a representative nember of generation $t$ by $-\left(1+\mathrm{r}_{\mathrm{t}+1}\right) \bar{\tau}_{t}^{1}+(1+\mathrm{n}) \bar{\tau}_{t+1}^{1}-(1+\mathrm{n}) \theta_{\mathrm{t}+1} \mathrm{~g}_{\mathrm{t}+1}$. The unbalanced budget scheme with the age-independent taxes (the double overbar scheme) adds the amount $-\overline{\bar{\tau}}_{t+1}-\left(1+r_{t+1}\right) \overline{\bar{\tau}}_{t}$ to the period $t+1$ value of the lifetime resources of a representative member of generation t. Equation (IV.13) equates the two.

Note that the homogeneous part of equation (IV.13) changes sign each period (imparting a sav-tooth pattern) and grows at a proportional rate $1+r$ in absolute value. The saw-tooth pattern of tax receipts is passed on to the value of the per capita debt through the government budget identity under the double overbar policy, given in (IV.14) below.

$$
\begin{gathered}
\mathrm{p}_{\mathrm{t}}^{\bar{b}}{ }_{t+1}=\left(1+\omega_{\mathrm{t}+1}\right)^{-1}(1+\mathrm{n})^{-1}\left(1+\mathrm{r}_{\mathrm{t}}\right) \mathrm{p}_{\mathrm{t}-1} \overline{\bar{b}}_{\mathrm{t}}+\left(1+\omega_{\mathrm{t}+1}\right)^{-1}(1+\mathrm{n})^{-1} \mathrm{~g}_{\mathrm{t}} \\
-\left(1+\omega_{\mathrm{t}+1}\right)^{-1}(1+\mathrm{n})^{-2} \theta_{\mathrm{t}}^{-1}(2+\mathrm{n}) \overline{\bar{\tau}}_{t}
\end{gathered}
$$

Equations (IV.8) and (IV.14) imply that

$$
\begin{aligned}
\mathrm{p}_{\mathrm{t}}^{\bar{b}}{ }_{t+1}=- & \left(1+w_{\mathrm{t}+1}\right)^{-1}\left(1+r_{t}\right) \mathrm{p}_{\mathrm{t}-1} \bar{b}_{t}-\left(1+w_{\mathrm{t}+1}\right)^{-1} \mathrm{~g}_{\mathrm{t}} \\
& +(1+\mathrm{n})^{-1} \theta_{\mathrm{t}+1}^{-1}(2+\mathrm{n}) \bar{\tau}_{t}^{-1}\left(\Theta_{\mathrm{t}}\right)
\end{aligned}
$$

Equation (IV.15) can be reuritten as

$$
\mathrm{p}_{\mathrm{t}} \overline{\overline{\mathrm{B}}}_{\mathrm{t}+1}=-(1+\mathrm{n})\left(1+\mathrm{r}_{\mathrm{t}}\right) \mathrm{p}_{\mathrm{t}-1} \overline{\mathrm{B}}_{\mathrm{t}}-(1+\mathrm{n}) \mathrm{G}_{\mathrm{t}}+(2+\mathrm{n}) \bar{\tau}_{\mathrm{t}}^{-1} \mathrm{~L}_{\mathrm{t}}
$$

The value of the public debt under the age-independent tax, unbalanced budget policy, $p_{t} \overline{\bar{B}}_{t+1}$, is likely to zig-zag from a positive value in one 
period to a negative value in the next. If, for instance, $\bar{\tau}_{t}^{1}$ and $L_{t}$ vere constant over time, the saw-tooth pattern of the public debt, with debt in the homogeneous equation of (IV.16) having a grouth factor of $-\left(1+r_{t}\right)$ each period, (as signaled in Calvo and Obstfeld [1988b] for an economy without population growth or productivity growth) is immediately apparent.

Over a two-period horizon, the public debt evolves according to

$$
\begin{aligned}
p_{t} B_{t+2}= & (1+n)^{2}\left(1+r_{t+1}\right)\left(1+r_{t}\right) p_{t-1} B_{t}-(1+n)\left[G_{t+1}-(1+n)\left(1+r_{t+1}\right) G_{t}\right] \\
& +(2+n)\left[\bar{\tau}_{t+1}^{1}-\left(1+r_{t+1}\right) \bar{\tau}_{t}^{1}\right] L_{t+1}
\end{aligned}
$$

Consider the simple example where $G_{t+1}=G_{t}=0$ and $\bar{\tau}_{t+1}^{1}=\bar{\tau}_{t}^{1}=\bar{\tau}^{-1}$ for all $t \geq 0$. Equation (IV.17) simplifies to

$$
\mathrm{p}_{\mathrm{t}} \overline{\bar{B}}_{\mathrm{t}+2}=(1+\mathrm{n})^{2}\left(1+\mathrm{r}_{\mathrm{t}+1}\right)\left(1+\mathrm{r}_{\mathrm{t}}\right) \mathrm{p}_{\mathrm{t}-1} \overline{\bar{B}}_{\mathrm{t}}-(2+\mathrm{n}) \mathrm{r}_{\mathrm{t}+1} \bar{\tau}_{\mathrm{t}+1}
$$

When $\bar{\tau}$ is negative (the balanced-budget scheme redistributes from the old to the young) and $r_{t+1}$ is non-negative, the public debt will, over a two-period horizon grow at a proportional rate at least equal to the sum of the real interest rate and the growth rate of population. If $n$ is non-negative, the sequence of the public debt will therefore have infinite subsequences that are characterized by Ponzi finance. Public credit too vill, over a two-period interval, grow at a rate asymptotically equal to the sum of the interest rate and the growth rate of population. Note that "subsequence Ponzi finance" is "essential" in this case.

The total resource transfer of the young generation to the government under the double overbar regime evolves according to

$$
\left.\mathrm{p}_{\mathrm{t}} \overline{\bar{B}}_{\mathrm{t}+1}+\overline{\bar{\tau}}_{\mathrm{t}} \mathrm{L}_{\mathrm{t}}=-(1+\mathrm{n})\left(1+\mathrm{r}_{\mathrm{t}}\right)\left(\mathrm{p}_{\mathrm{t}-1} \overline{\bar{B}}_{\mathrm{t}}+\overline{\bar{\tau}}_{\mathrm{t}-1} \mathrm{~L}_{\mathrm{t}-1}\right)+\bar{\tau}_{\mathrm{t}}^{-1} \mathrm{~L}_{\mathrm{t}}+(1+\mathrm{n})\left(1+\mathrm{r}_{\mathrm{t}}\right) \bar{\tau}_{\mathrm{t}-1}^{1} \mathrm{~L}_{\mathrm{t}-1}\right)
$$




\section{Corollary 1.}

Proposition 1. holds when the restriction that per capita taxes are equal for both generations alive in any given period is replaced by the restriction that taxes per generation alive in any given period are equal.

When the age-restricted tax policy is given by Case $2 a$ of Section III, that is by equal taxes or transfers per generation, or $\overline{\bar{\tau}}_{t}^{1}(1+n)=\overline{\bar{\tau}}_{t-1}^{2}$, the public debt path that supports any balanced budget equilibrium with unrestricted taxes and transfers is given by

$$
p_{t} \overline{\bar{B}}_{t+1}=-\left(1+r_{t}\right) p_{t-1} \bar{B}_{t}-G_{t}+2 \bar{\tau}_{t}^{-1} L_{t}
$$

In the simple example when $\bar{\tau}_{t}^{1}=\bar{\tau}^{1}$ for all $t$ and $L_{t}$ is constant, the public debt (and the public credit) vill, over a two period horizon, grow asymptotically at the rate of interest. Subsequence Ponzi finance is again "essential".

The total resource transfer of the young generation to the government under the double overbar regine evolves according to

$$
\mathrm{p}_{\mathrm{t}} \overline{\bar{B}}_{\mathrm{t}+1}+\overline{\bar{\tau}}_{\mathrm{t}} \mathrm{L}_{\mathrm{t}}=-\left(1+\mathrm{r}_{\mathrm{t}}\right)\left(\mathrm{p}_{\mathrm{t}-1} \overline{\bar{B}}_{\mathrm{t}}+\overline{\bar{\tau}}_{\mathrm{t}-1} \mathrm{~L}_{\mathrm{t}-1}\right)+\overline{\bar{\tau}}_{\mathrm{t}}^{-1} \mathrm{~L}_{\mathrm{t}}+\left(1+\mathrm{r}_{\mathrm{t}}\right) \bar{\tau}_{\mathrm{t}-1}^{1} \mathrm{~L}_{\mathrm{t}-1}
$$

\section{Corollary 2.}

Proposition 1. holds when the restriction that per capita tazes are equal for both generations alive in any given period is replaced by the restriction that taxes per efficiency unit of labor in any given period are equal.

When the age-restricted tax policy is given by Case $2 c$ of Section III, 
that is by equal taxes or transfers per unit of efficiency labor, or $\overline{\bar{\tau}}_{t}^{1}=\left(1+w_{t}\right) \overline{\bar{\tau}}_{t-1}^{2}$, the public debt path that supports any balanced budget equilibrium with unrestricted taxes and transfers is given by

$$
p_{t} \bar{B}_{t+1}=-\left(1+\omega_{t}\right)(1+n)\left(1+r_{t}\right) p_{t-1} \bar{B}_{t}-\left(1+\omega_{t}\right)(1+n) G_{t}+\left[2+n+\omega_{t}(1+n)\right] \bar{\tau}_{t}^{-1} L_{t}
$$

Again taking the simple example where $G_{t}=0$ and $\bar{\tau}_{t}^{1}=\bar{\tau}^{-1}$ for all $t \geq 0$, it is easily seen that over a 2-period interval, the public debt (and the public credit) will asymptotically grow at the sum of the interest rate, the growth rate of population and the growth rate of productivity. If the growth rate of efficiency labor is non-negative, Ponzi finance will be feasible and "essential".

The total resource transfer of the young generation to the government under the double overbar regime evolves according to

$$
\begin{aligned}
p_{t} \overline{\bar{B}}_{t+1}+\overline{\bar{\tau}}_{t} L_{t}=-\left(1+w_{t}\right) & (1+n)\left(1+r_{t}\right)\left(p_{t-1} \overline{\bar{B}}_{t}+\overline{\bar{\tau}}_{t-1} \mathrm{~L}_{t-1}\right) \\
& +\bar{\tau}_{t}^{-1} L_{t}+\left(1+w_{t}\right)(1+n)\left(1+r_{t}\right) \bar{\tau}_{t-1}^{1} L_{t-1}
\end{aligned}
$$

\section{Proposition 5.}

Given an initial value $k_{0}$ and a sequence of exhaustive public spending $g_{t^{\prime}}$ $t \geq 0$, any equilibrium for $p_{t}, k_{t}, c_{t}^{1}$ and $c_{t-1}^{2}$ for all $t \geq 0$ that can be supported with a balanced budget and unrestricted lump-sum taxes and transfers, can also be supported with taxes and transfers that are required to have the same sign during the lifetime of each generation, provided unbalanced budgets are allowed.

Proof: Under the balanced budget (single overbar) reference policy, $\bar{B}_{t}=0$ and $\bar{\tau}_{t}^{1} L_{t}+\bar{\tau}_{t-1}^{2} L_{t-1}=G_{t}$ for all $t \geq 0$. Under the double overbar policy, we have $p_{t} \overline{\vec{B}}_{t+1} \equiv\left(1+r_{t}\right) p_{t-1} \overline{\vec{B}}_{t}+G_{t}-\overline{\bar{\tau}}_{t}^{1} L_{t}-\overline{\bar{\tau}}_{t-1}^{2} L_{t-1}$ and $\overline{\bar{\tau}}_{t}^{2}=\lambda_{t} \overline{\bar{\tau}}_{t}^{1}$, 
$\lambda_{t}>0$ for all $t \geq 0$. For the two policies to support the same equilibrium (and for the double overbar policy to satisfy the solvency constraint if the single overbar policy satisfies it) it must be the case that $\mathrm{p}_{t} \overline{\bar{B}}_{\mathrm{t}+1}+\overline{\bar{\tau}}_{\mathrm{t}}^{-1} \mathrm{~L}_{\mathrm{t}}=\bar{\tau}_{\mathrm{t}}^{1}$ (or equivalently that $\left(1+r_{t}\right) p_{t-1} \bar{B}_{t}-\overline{\bar{\tau}}_{t-1}^{2} L_{t-1}=-\bar{\tau}_{t-1}^{2} L_{t-1}$ ).

The behavior of the public debt under the double overbar policy is governed by

$$
P_{t-1} \overline{\bar{B}}_{t}=\left(1+r_{t}+\lambda_{t-1}\right)^{-1}\left[\bar{\tau}_{t}^{-1} L_{t}+\lambda_{t-1} \bar{\tau}_{t-1}^{1} L_{t-1}-G_{t}\right]
$$

Noting that

$$
\mathrm{p}_{\mathrm{t}-1} \overline{\mathrm{B}}_{\mathrm{t}}+\overline{\bar{\tau}}_{\mathrm{t}-1}^{1} \mathrm{~L}_{\mathrm{t}-1}=\bar{\tau}_{\mathrm{t}-1}^{1} \mathrm{~L}_{\mathrm{t}-1}
$$

ve see that equations (IV.20) and (IV.21) can be satisfied through the appropriate choice of (positive or negative) values for $\mathrm{p}_{t-1} \overline{\bar{B}}_{t}$ and $\overline{\bar{\tau}}_{t-1}^{1}$, for any given positive value of $\lambda_{t-1}$ and exogenously given feasible values of $\bar{\tau}_{t}^{1}$, $\bar{\tau}_{t-1}^{1}$ and $G_{t} \cdot \square$

Consider, for instance, the special case where $\lambda_{t}=1$, that is there either has to be an equal tax or an equal transfer each period over the lifetime of each generation. Equation (IV.20) then simplifies to

$$
\mathrm{p}_{\mathrm{t}-1} \overline{\bar{B}}_{\mathrm{t}}=\left(2+\mathrm{r}_{\mathrm{t}}\right)^{-1}\left[\bar{\tau}_{\mathrm{t}}^{-1} \mathrm{~L}_{\mathrm{t}}+\bar{\tau}_{\mathrm{t}-1-1}^{1} \mathrm{~L}_{\mathrm{t}-1}-\mathrm{G}_{\mathrm{t}}\right]
$$

Since the stock of debt can be negative as vell as positive, the restriction that $\overline{\bar{\tau}}_{t}^{1}$ and $\overline{\bar{\tau}}_{t}^{2}$ must have the same sign (or even be equal), does not prevent the government from replicating any equilibrium supported by a balanced budget policy with unrestricted taxes and transfers.

Since, by assumption, taxes paid to the government cannot change sign over the life cycle, Ponzi finance is only possible under the double overbar policy if the interest rate is below the growth rate of efficiency labor. This is obvious from (IY.20), as $\bar{\tau}_{t}^{1} L_{t}+\lambda_{t-1} \bar{\tau}_{t-1}^{-1} L_{t-1}-G_{t}$ cannot have a 
long-run growth rate in excess of the growth rate of efficiency labor.

Proposition 3 states that public debt and deficits (and by implication Ponzi finance) are redundant policy instruments as long as the fiscal authority has unrestricted age-specific lump-sum taxes and transfers. Proposition 4 and its two Corollaries and Proposition 5 emphasize that a fiscal authority with a restricted tax-transfer instrumentarium may be able to use public debt and deficits as perfect substitutes for the missing age-specific taxes and transfers, provided the government solvency constraint is specified as in (III.8a,b and c). Essential (subsequence) Ponzi finance may be a feature of these government borrowing and lending strategies (vide Proposition 4 and its Corollaries).

Our approach to government solvency has implications for the empirical approaches to testing for government solvency (see e.g. Hamilton and Flavin [1986], Wilcox [1989], Corsetti [1990], Grilli [1990] and Buiter and Patel [1991]). All these papers used variants of the convergence-in-expectation version of the conventional solvency criterion given in (III.3b), involving the long-run behavior of the discounted public debt, that is, they tested $\lim _{T \rightarrow \infty} \delta_{t-1+T} p_{t-1+T} b_{t+T} \equiv$ $(1+n)^{-1} \operatorname{lims}_{T \rightarrow \infty} t-1+T^{p_{t-1}} T^{B} t+T=0$ (or its expectational counterpart).

Ye have seen that even in economies in which the long-run rate of interest exceeds the long-run growth rate of efficiency labor, Ponzi finance may be feasible. As long as (1) the tax burden can vary freely over the life cycle of each generation (specifically if they can make net positive transfer payments to a generation when it is young and impose a net positive tax when it is old, and (2) the transfers and taxes can grov at least as fast as the rate of interest, the potential for Ponzi finance exists. Note that the empirically unlikely zig-zag pattern of the debt need not occur when the two 
generations alive during any given period can be treated differently by the tax-transfer system (see the proof of Proposition 5 ).

(v) CONCLUSION.

Merely looking at the stock of public debt, without attempting to evaluate the total impact of the fiscal-financial policy rules on what Auerbach, Gokhale and Kotlikoff [1991] have called the "generational accounts" can be very misleading as an indicator of the degree of financial crowding out pressure in the economy. We showed that, given a sufficiently rich tax-transfer menu, the government could achieve any desired intergenerational redistribution and insurance with public debt, without it or indeed with public credit. It is when tax-transfer options are constrained that the option of public borrowing or lending becomes valuable, both for intergenerational redistribution and for intergenerational insurance.

The tax-smoothing proposition demonstrates how public debt can be useful for conventional (not uncertainty-related) efficiency reasons in the absence of non-distortionary taxes and transfers. Our paper complements this by showing how public debt can be useful in the pursuit of distributional objectives and efficient intergenerational insurance schemes, if there is a restricted menu of lump-sum taxes and transfers.

An important part in the proof of the proposition that government debt can be used to take over the intergenerational redistribution and insurance roles of missing age-specific taxes and transfers, was our specification of the government solvency constraint. $A$ government is solvent if is does not pursue policies that force the private sector into bankruptcy when there exists an alternative policy that would not do so. The private sector is bankrupt when the non-negativity constraints on consumption by the young, 
consumption by the old or the capital stock become binding. The stock of public debt is limited by the condition that the total amount of resources taken by the government frow the young, whether through borroving or through taxes, cannot exceed the vage income of the young. The stock of public credit is likevise limited by the condition that the total amount of resources taken by the government from the old, whether through the old servicing their debt to the government or through taxes, cannot exceed the capital income of the old.

Provided the government can make net transfer payments to a generation when it is young and impose net taxes on that generation when it is old, and provided these transfer payments and taxes can grow at least at the rate of interest, Ponzi finance is possible, regardless of the relationship between the interest rate and the growth rate, and regardless of whether or not the economy is dynamically inefficient or Pareto efficient. If either of these assumptions is violated, our solvency constraint implies (when the long-run interest rate exceeds the long-run growth rate of efficiency labor) that the conventional solvency constraint applies: the sequence of public debt discounted at the rate of interest converges to zero. 


\section{BEFERENCES}

Abel, Andrev B. [1988], "The Implications of Insurance for the Efficacy of Fiscal Policy", KBER Vorking Paper No. 2517, February.

Auerbach, Alan J., Jagadeesh Gokhale and Laurence J. Kotlikoff [1991], "Generational Accounts- $A$ meaningful Alternative to Deficit Accounting", NBER Yorking Paper No. 3589, January.

Barro, Robert J. [1976], "Reply to Feldstein and Buchanan", Journal of Political Econony, 84, April, pp. 343-49.

Political Econony, 87, pp. 940-971.

Blanchard, 0.J., Jean Claude Chouraqui, Robert P. Hagemann, and Nicola Sartor, "The sustainability of fiscal policy: nev answers to an old question", OECD Econonic Studies, No. 15, pp. 7-36, Autumn, pp. 7-36.

Blanchard, O. J. and P. Veil [1992], "Dynamic Efficiency, The Riskless Rate, and Debt Ponzi Games Under Uncertainty", NBER Vorking Paper No. 3992, February.

Bohn, Henning [1990], "Sustainability of Budget Deficits in a Stochastic Economy", Mimeo, Department of Finance, The tharton School, University of Pennsylvania.

[1991], "The sustainability of budget deficits with lump-sum and with income-based taxation", Journal of Money, Credit and Banking, 23, No. 3, Pt. 2, August, pp. 580-604.

Buiter, Villem H. [1985], "A guide to public sector debt and deficits", Econonic Policy, 1, November, pp. 13-79.

[1990], "Debt Neutrality, Redistribution and Consumer Heterogeneity: A Survey and Some Extensions", in William C. Brainard, William D. Nordhaus and Harold W. Watts eds, Money, Macroeconomics and Economic Policy, MIT Press, Cambridge MA; also in V.H. Buiter, Principles of Budgetary and Financial Policy, pp. 183-222, MIT Press, Cambridge, MA.

and Kenneth 4 . Kletzer [1990], "Fiscal Policy, Interdependence and Efficiency", NBER Vorking Paper No. 3328, April. and Noncooperative Fiscal Policy," Journal of Econonic Dynanics and Control, 15, pp. 215-244.

and Urjit R. Patel [1992], "Debt, deficits and inflation: An Application to the public finances of India", Journal of Pablic Econonics, forthcoming. 
Calvo, Guillermo A. and Maurice Obstfeld [1988a], "Optimal Time-Consistent Fiscal Policy with Finite Lifetimes," Econonetrica 56(2), March, 411-432. and [1988b], "Optimal Time-Consistent Fiscal Policy with Finite Lifetimes: Analysis and Extensions", in E. Helpman, A. Razin and E. Sadka (eds.), Econonic Effects of the Government Budget, 163-198, MIT Press, Cambridge, Ma.

Corsetti, Giancarlo [1990], "Testing for solvency of the public sector: In application to Italy", Yale University, Economic growth Center Discussion Paper No. 617, September.

Diamond, Peter A. [1965], "National Debt in a Neo-Classical Growth Model," Anerican Econonic Review 55 1126-1150.

Eaton, J. and K. Rosen [1980], Taxation, Human Capital and Uncertainty", Inerican Econonic Review, 70, pp. 705-715.

Enders, Y. and B.E. Lapan [1982], "Social Security Taxation and Intergenerational Risk Sharing", International Econonic Revieq, 23, pp. $647-658$.

Feldstein, Martin [1988], "The Effects of Fiscal Policies Then Incomes are Dncertain: A Contradiction to Ricardian Equivalence", Anerican Bcononic Reviev, 78, pp. 14-23.

[1989], "Imperfect Annuities Markets, Unintended Bequests, and the Optimal Age Structure of Social Security Benefits.", NBER Vorking Paper No. 2820, January.

Fischer, Stanley [1983], "Velfare aspects of government issue of indexed bonds", in $\mathbb{R}$. Dornbusch and $M$. H. Simonsen, Inflation, Debt, and Indexation, The MIT Press, Cambridge, MA, pp. 223-246.

Gale, Douglas [1990], "The efficient design of public debt", in R. Dornbusch and $\mathbb{M}$. Draghi eds. Issnes in Debt lanagenent, forthcoming.

Gordon, Roger K. and Hal R. Varian [1988], "Intergenerational Risk Sharing", Jonrnal of Pablic Econonics, 37, pp. 185-202.

Grilli, V. [1989], "Seigniorage in Europe", in 1. de Cecco and A. Giovannini eds. A European Central Bant?, Cambridge University Press, Cambridge J.R., pp. $53-79$.

Hamilton, J.D. and M.A. Flavin [1986], "On the limitations of government borrowing: A framework for empirical testing", Anerican Econonic Reviev, 76, September, pp. 808-819.

Hayashi, Fumio, Joseph Altonji and Laurence Kotlikoff [1991], "Risk-Sharing, Altruism, and the Factor Structure of Consumption", NBER Vorking Paper No. 3834 , September.

Kaplow, Louis [1991], "A note on taxation as social insurance for uncertain labor income", NBER Working Paper No. 3708, May. 
Rimball, Miles S. and N. Gregory Mankiw [1989], "Precautionary Saving and the Timing of Taxes", Journal of Political Econony, 97, pp. 863-879.

Xremers, Jeroen [1989], "D.S. Federal Indebtedness and the Conduct of Fiscal Policy, Journal of Monetary Econonics, 23, pp. 219-38.

McCallun, Bennett T. [1984], "Are bond-financed deficits inflationary? A Ricardian analysis", Journal of Political Econony, 92, February, pp. 123-135

Merton, R.C. [1984], "On the Role of Social Security as a Means for Efficient Risk-Bearing in an Economy where Hunan Capital is not Tradable", in Zvi Bodie and John Shoven, Eds. Financial Aspects of the Onited States Pension Systen, Oniversity of Chicago Press, Chicago, Ill.

D'Connell, Stephen $\Lambda$. and Stephen P. Zeldes [1988], "Rational Ponzi Games" International lcononic Review, 29, pp. 431-450.

Pagano, Marco [1988], "The management of public debt and financial markets", in F.Giavazzi and L. Spaventa eds. High Public Debt: the Italian Experience, Cambridge University Press, pp. 135-166.

Samuelson, Paul A. [1958], "An exact consumption-loan model of interest with or without the social contrivance of money", Journal of Political Econony, 66, pp. 467-482.

Shell, Karl [1971], "Notes on the Economics of Infinity", Jonrnal of Political liconony, 79, pp. 1002-1011.

Spaventa, L. [1987], "The growth of public debt: sustainability, fiscal rules, and monetary rules", IT Staff Papers, 34.

[1988], "Discussion", in F.Giavazzi and L. Spaventa eds. High Public Debt: the Italian Experience, Cambridge University Press, pp. 173-176.

Stiglitz, J. [1983], "On the Relevance or Irrelevance of Public Financial Policy: Indexation, Price Rigidities, and Optimal Yonetary Policies", in R. Dornbusch and Kario Henrique Simonsen, eds. Inflation, Debt and Indexation, MIT Press, Cambridge, Mi., pp. 183-222.

Varian, H.R. [1980], "Redistributive taxation as social insurance", Journal of Public Economics, 17, pp. 49-68.

Vilcox, D.W. [1989], The sustainability of government deficits: Implications of the present value borroving constraint", Journal of Yoney, Credit and Banking, 21, August, pp. 291-306.

Vilson, Charles A. [1981], "Equilibrium in dynamic models with an infinity of agents", Journal of Economic Theory, 24, pp. 95-111.

Zilcha, Itzhak [1990], "Dynamic Efficiency in Overlapping Generations Models with Stochastic Production", Journal of Econonic Theory, 52, pp. 364-379. 


\section{NOTES}

With distortionary (non-lump-sum) taxes and transfers, real equilibria will almost always be affected by the ability, of fered by unbalanced budgets, to vary the pattern over time of the excess burdens associated vith the use of distortionary instruments. See e.g. Barro [1979].

2See Buiter [1990] for a discussion of the roles of different kinds of heterogeneity in a number of standard OLG models.

II is the institution of government that must be infinite-lived, not any particular set of incumbent politicians. Specifically, what is required that a government does not repudiate the debt incurred by its predecessors.

Earlier versions of these propositions can be found in Buiter and Eletzer $[1990,1991]$.

For an analysis of private intergenerational risk sharing motivated through altruism see Bayashi, Altonji and Iotlikoff [1991].

spart from the incomplete market participation that is intrinsic to OLG models without the institution of hereditary slavery, more standard types of insurance market failures can also create a potential velfare-improving role for taxes, transfer payments and public debt. For instance, in the presence of uncertain lifetimes (a feature that is absent from our model), a compulsory social security retirement 8 cheme can provide an annuity that is actuarially fairer than those provided by the voluntary private annuities market which is adversely affected by adverse selection (see Abel [1988] and Feldstein (1989)). Eaton and Rosen [1980], Varian [1980], Feldstein [1988], Rimball and Yankiw [1989] and Kaplow [1991] discuss how income taxation can serve as social insurance against uncertainties in labor income. The positive and welfare consequences of such social insurance will of course depend on the availability and nature of private insurance arrangements and the reasons for the absence of a set of complete insurance markets. Typically, adverse selection problems can be mitigated by compulsory social insurance through the tax-transfer mechanism while moral hazard problems affect efficient public provision of insurance as much as private provision.

illowing for longer maturity debt vould add notation but vould not affect the equivalence results.

The single-period utility function $v$ is twice continuously differentiable, strictly concave, increasing in $c^{1}$ and $c^{2}$ and satisfies the Inada conditions.

'Since taxes, coupon payments and the marginal product of capital can be stochastic, it may not be possible to satisfy (II.3a,b) for non-negative values of $c_{t}^{1}$ and/or $c_{t}^{2}$. While labor productivity and the marginal product of capital are assumed to be positive, it may not be possible to satisfy the constraints $c_{t}^{1} \geq 0, c_{t-1}^{2} \geq 0, \mathbb{R}_{t+1} \geq 0$ and $G_{t} \geq 0$ for arbitrary public debt, tax and transfer sequences. Our goverament solvency constraint is in fact exactly the constraint that households are not forced into bankruptcy by government policy.

Note that for arbitrary government policies, private bankruptcy might occur even if individuals cannot borrow from the government $\left(b^{d} \geq 0\right)$, because 
even without private debt to the government, the old might not have enough resources to pay the stochastic taxes. If the constraints $c_{t}^{1}, c_{t}^{2} \geq 0$ vere imposed, even non-contingent debt issued by private individuals $\left(b^{d}<0\right)$ would in general be risky debt, with gross rate of return $1+r_{t+1}$ if there is no bankruptcy $\left(c_{t}^{2}>0\right)$ and gross rate of return $\max \left\{0,\left[\left(1+\rho_{t+1}\right) k_{t+1}^{d}-\tau_{t}^{2}\right] /\left(-b_{t+1}^{d}\right)\right\}$ otherwise. Vith or without private debt to the government, the old might not have enough resources to pay taxes. Assuming that taxes owed to the government have the same priority as interest owed to the government, actual taxes plus interest paid by the old would be given by $\min \left\{\tau_{t}^{2}+\gamma_{t+1} b_{t+1}^{d},\left(1+\rho_{t+1}\right) k_{t+1}^{d}\right)$. It is even possible that the young would not be able to pay their taxes. This would be the case if $w_{t}$ plus the maximal amount the young could borrow were less than $\tau_{t}^{1}$. Allowing for this would greatly complicate the exposition but would not affect our equivalence results, as long as taxes and interest owed vould be subject to the same treatment.

10Ve do not impose the constraints $k^{d} \geq 0$ and $b^{d} \geq 0$. Since in the household decision problem $k^{d}$ stands for equity, that is ownership claims to the stock of physical capital, there is no reason the household cannot go short in it. Ve could also allow households to issue state-contingent debt. What ve are implicitly assuming in our formal model is that the debt they issue is identical to government debt. The introduction of private debt does therefore not increase the asset menu.

1The consumer's optimum vill be turn out to be interior because (1) the utility function satisfies the Inada conditions, (2) the vage rate, the gross return on debt and the gross return on capital are positive and (3) government policy does not drive consumers to bankruptcy. Equations (II.4a,b) anticipate points (2) and (3), which are introduced later in Section II, respectively in Section III.

${ }^{12}$ Note that when debt is riskless, (II.4a,b) imply the familiar risk premium for capital formula : $E_{t} \rho_{t+1}=r_{t+1}-\operatorname{Cov}_{t}\left[\rho_{t+1}, v^{\prime}\left(c_{t}^{2}\right)\right]$, where $\operatorname{Cov}_{t}$ denotes the conditional variance operator. $E_{t} v^{\prime}\left(c_{t}^{2}\right)$

13Public consumption can be an argument in the private utility function. As long as it enters in an additively separable way, it vill not affect the first-order conditions for private consumption. Since we are interested in characterizing feasible fiscal strategies rather than optimal ones, ve model public consumption as a pure vaste of resources. Public sector capital formation could be added to our list of fiscal instruments in a straightforward manner and is omitted only because of space limitations.

110ften the weaker solvency criterion that (III.3) hold in expectation only, is

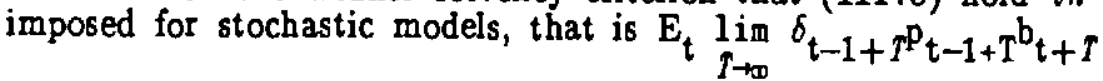

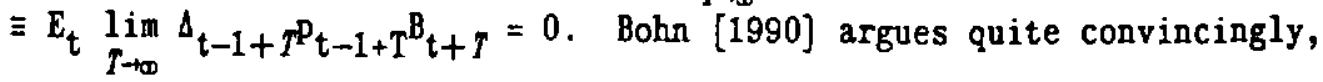


hovever, that the solvency criterion should apply to all realizations of the discounted debt process, and not just to its mathematical expectation. See also Blanchard and Veil [1992].

15then only the expectation of the discounted debt is required to go to zero in the limit, equation (III.4) is replaced by

$$
\delta_{\mathrm{t}-1} \mathrm{P}_{\mathrm{t}-1} b_{t}=\mathrm{E}_{\mathrm{t}} \lim _{\mathrm{T} \rightarrow \infty}\left[\sum_{i=0}^{\mathrm{T}-1}\left(\theta_{\mathrm{t}+\mathrm{i}+1}\right)^{-1}\left[\frac{\tau^{1} t+i}{I+n}+\left[\frac{1}{T+n}\right]^{2} \tau_{t+i-1}^{2}-\frac{\mathrm{g}_{\mathrm{t}+\mathrm{i}}}{1+\mathrm{n}}\right] \delta_{t+i}\right]
$$

10If ve extended the government financial liability menu, say by allowing longer maturity debt, the definition would have to be adapted to the specific set of government debt instruments alloved. The statement that the government never runs a primary surplus, always defines Ponzi finance.

17This is in the spirit of D'Connell and Zeldes [1988], who point out that in order for the government to run a "rational" Ponzi scheme, a rational private sector must be willing to be at the receiving end of such a scheme.

${ }^{18}$ Note that in our model both the wage rate and the marginal product of capital are positive, because of ve restrict the level of labor-augmenting productivity to be postive. Without a government sector, private bankruptcy would therefore not occur. If the technology vere to permit private bankruptcy even vithout a government, our solvency constraint vould be modified as follows. The government does not select sequences for taxes, transfer payments, debt and exhaustive spending that vill cause the non-negativity constraints on consumption by both generations and on the capital stock to become binding if there exist alternative seguences of the government instruments that would avoid this.

${ }^{19}$ Note that the total transfer to the government by the young during period $t$ evolves according to

$$
\mathrm{P}_{\mathrm{t}} \mathrm{B}_{\mathrm{t}+1}^{* *}+\tau_{\mathrm{t}}^{1^{* *}} \mathrm{~L}_{\mathrm{t}}=\left(1+\mathrm{r}_{\mathrm{t}}\right)\left(\mathrm{p}_{\mathrm{t}-1} \mathrm{~B}_{\mathrm{t}-1}^{* *}+\tau_{\mathrm{t}-1}^{1^{*}} \mathrm{~L}_{\mathrm{t}-1}\right)+\left[(1+\mathrm{n}) \tau_{\mathrm{t}}^{1^{*}}-\left(1+\mathrm{r}_{\mathrm{t}}\right) \tau_{\mathrm{t}-1}^{*}\right] \mathrm{L}_{\mathrm{t}-1}
$$

${ }^{20}$ Note that such a tax is not perceived by those investing in government debt as a "tax on debt" affecting expected returns from holding debt, even if the tax is fully anticipated. It is perceived as lump-sum, that is the amount paid is perceived as independent of the actions of the tax payer, including her portfolio choice.

2McCallun's specification of the private sector solvency constraint (which is not vell motivated) still implies that the long-run growth rate of the public debt must the less than the private rate of time preference.

$220 r$, equivalently, if $\lim _{t \rightarrow \infty}\left\{\Delta_{t}\left[\left(g_{t}-\left(1+f^{\prime}\left(k_{t}\right)\right) k_{t}\right) \theta_{t}-\tau_{t}^{1}\right](1+n)^{t}\right\}=0$,

23Strictly speaking this should be $\lim _{t \rightarrow \infty} \inf _{t \leq t<\infty}\left\{\Delta_{t} p_{t} B_{t+1}\right\} \leq 0$ and

$\lim _{t \rightarrow \infty} \sup _{t^{\prime}}\left\{\Delta_{t} p_{t} B_{t+1}\right\} \geq 0$. If the lim inf and the lim sup are both equal to zero then $\lim _{t \rightarrow \infty} \Delta_{t} p_{t} B_{t+1}=0$.

24that we require, strictly speaking, is the the sequences of taxes and 
transfers per generation, $\left\{\tau_{t}^{1} \mathrm{~L}_{t}\right\}_{t=0}^{\infty}$ and $\left\{\tau_{t-1}^{2} \mathrm{~L}_{t-1}\right\}_{t=0}^{\infty}$ have infinite subsequences $\left\{\tau_{t_{j}}^{1} L_{t_{j}}\right\}_{t_{j}=0}^{\infty}$ and $\left\{\tau_{t_{j}-1}^{2}\right)_{t_{j}=0}^{\infty}$ whose elements have a growth rate at least as high as the interest rate.

${ }^{25}$ Note that, although $\overline{\bar{\tau}}_{t}^{2}$ can depend on $\theta_{t+1}$ and therefore on $\theta_{t+1}, \overline{\bar{\tau}}_{t}^{2}-\bar{\tau}_{t}^{2}$ can depend only on $\theta_{t}$ and therefore not on $\theta_{t+1}$. If you tax the young more in period $t$ under the double overbar policy than under the single overbar policy, you will borrow less (equation (III.9)). In period $t+1$ the taxes on the old generation can be lower under the double overbar policy by $\left(1+r_{t+1}\right)$ times the amount by which the taxes they paid in period $t$ (when they were young) were higher. This leaves the life-time budget constraint unaffected. 